\title{
Clinical Management of Pediatric Acute-Onset Neuropsychiatric Syndrome: Part II-Use of Immunomodulatory Therapies
}

\author{
Jennifer Frankovich, MD, MS, ${ }^{1,2}$ Susan Swedo, MD, ${ }^{3}$ Tanya Murphy, MD, MS, ${ }^{4}$ Russell C. Dale, MD, \\ Dritan Agalliu, $\mathrm{PhD}^{6}$, Kyle Williams, MD, PhD, Michael Daines, MD, Mady Hornig, MD, MA, \\ Harry Chugani, MD, ${ }^{10}$ Terence Sanger, MD, PhD, ${ }^{11}$ Eyal Muscal, MD, MS, ${ }^{12}$ Mark Pasternack, MD, ${ }^{13}$ \\ Michael Cooperstock, MD, MPH, ${ }^{14}$ Hayley Gans, MD, ${ }^{15}$ Yujuan Zhang, MD, ${ }^{16}$ Madeleine Cunningham, PhD, ${ }^{17}$ \\ Gail Bernstein, MD, ${ }^{18}$ Reuven Bromberg, MD, ${ }^{19}$ Theresa Willett, MD, PhD, Kayla Brown, BA, ${ }^{1,2}$ \\ Bahare Farhadian, MSN, RN, FNP-C, ${ }^{1}$ Kiki Chang, MD, ${ }^{1,20}$ Daniel Geller, MD, \\ Joseph Hernandez, MD, PhD, ${ }^{1,2}$ Janell Sherr, MD, ${ }^{1,2}$ Richard Shaw, MD, ${ }^{20}$ Elizabeth Latimer, MD, \\ James Leckman, MD, PhD, ${ }^{23}$ and Margo Thienemann, MD ${ }^{1,20}$; PANS/PANDAS Consortium
}

\begin{abstract}
Introduction: Pediatric Acute-onset Neuropsychiatric Syndrome (PANS) is a clinically heterogeneous disorder with a number of different etiologies and disease mechanisms. Inflammatory and postinfectious autoimmune presentations of PANS occur frequently, with some clinical series documenting immune abnormalities in $75 \%-80 \%$ of patients. Thus, comprehensive treatment protocols must include immunological interventions, but their use should be reserved only for PANS cases in which the symptoms represent underlying neuroinflammation or postinfectious autoimmunity, as seen in the PANDAS subgroup (Pediatric Autoimmune Neuropsychiatric Disorders associated with Streptococcal infections).

Methods: The PANS Research Consortium (PRC) immunomodulatory task force is comprised of immunologists, rheumatologists, neurologists, infectious disease experts, general pediatricians, psychiatrists, nurse practitioners, and basic scientists with expertise in neuroimmunology and PANS-related animal models. Preliminary treatment guidelines were created in the Spring of 2014 at the National Institute of Health and refined over the ensuing 2 years over conference calls and a shared webbased document. Seven pediatric mental health practitioners, with expertise in diagnosing and monitoring patients with

\footnotetext{
${ }^{1}$ Stanford PANS Clinic and Research Program at Lucile Packard Children's Hospital, Stanford University School of Medicine, Palo Alto, California

${ }^{2}$ Pediatric Allergy, Immunology, and Rheumatology, Stanford University School of Medicine, Palo Alto, California.

${ }^{3}$ Pediatrics and Developmental Neuroscience Branch, National Institute of Mental Health, Bethesda, Maryland.

${ }^{4}$ Rothman Center for Pediatric Neuropsychiatry, Pediatrics and Psychiatry, University of South Florida Morsani College of Medicine, Tampa, Florida.

${ }^{5}$ Paediatrics and Child Health, Institute for Neuroscience and Muscle Research, the Children's Hospital at Westmead, University of Sydney, Sydney,

${ }^{6}$ Pathology and Cell Biology (in Neurology and Pharmacology), Columbia University, New York, New York.

${ }^{7}$ Pediatric Neuropsychiatry and Immunology Program in the OCD and Related Disorders Program, Harvard Medical School, Boston, Massachusetts.

${ }^{8}$ Allergy, Immunology, and Rheumatology, The University of Arizona College of Medicine Tuscon, Tuscon, Arizona.

${ }^{9}$ Epidemiology, Center for Infection and Immunity, Columbia University Medical Center, New York, New York.

${ }^{10}$ Pediatric Neurology, Nemours/Alfred I. duPont Hospital for Children, Wilmington, Delaware.

${ }^{11}$ Neurology, University of Southern California Pediatric Movement Disorders Center, Children's Hospital of Los Angeles, Los Angeles, California.

${ }^{12}$ Pediatric Rheumatology, Baylor College of Medicine, Houston, Texas.

${ }^{13}$ Pediatric Infectious Disease, Harvard Medical School, Boston, Massachusetts.

${ }^{14}$ Pediatric Infectious Diseases, University of Missouri School of Medicine, Columbia, Missouri.

${ }^{15}$ Pediatric Infectious Diseases, Stanford University School of Medicine, Stanford, California.

${ }^{16}$ Pediatric Rheumatology, Tufts University School of Medicine, Boston, Massachusetts.

${ }^{17}$ Microbiology and Immunology, College of Medicine, University of Oklahoma Health Sciences Center, Oklahoma City, Oklahoma.

${ }^{18}$ Child and Adolescent Psychiatry, University of Minnesota Medical School, Minneapolis, Minnesota.

${ }^{19}$ Pediatric Rheumatology, Miami Rheumatology, LLC, Miami, Florida.

${ }^{20}$ Psychiatry and Behavioral Sciences, Child and Adolescent Psychiatry, Stanford University School of Medicine, Palo Alto, California

${ }^{21}$ Pediatric OCD and Tic Disorder Program, Harvard Medical School, Boston, Massachusetts.

${ }^{22}$ Pediatric Neurology, Georgetown University Hospital, Washington, District of Columbia.

${ }^{23}$ Child Psychiatry, Psychiatry, Psychology and Pediatrics, Yale Child Study Center, Yale School of Medicine, New Haven, Connecticut.

(c) Jennifer Frankovich et al. 2017; Published by Mary Ann Liebert, Inc. This article is available under the Creative Commons License CC-BY-NC original work is properly cited. Permission only needs to be obtained for commercial use and can be done via RightsLink.
} Australia. (http://creativecommons.org/licenses/by-nc/4.0). This license permits non-commercial use, distribution and reproduction in any medium, provided the
\end{abstract}


PANS, were consulted to create categories in disease severity and critically review final recommendations. All authors played a role in creating these guidelines. The views of all authors were incorporated and all authors gave final approval of these guidelines. Results: Separate guidelines were created for the use of immunomodulatory therapies in PANS patients with (1) mild, (2) moderate-to-severe, and (3) extreme/life-threatening severity. For mildly impairing PANS, the most appropriate therapy may be "tincture of time" combined with cognitive behavioral therapy and other supportive therapies. If symptoms persist, nonsteroidal anti-inflammatory drugs and/or short oral corticosteroid bursts are recommended. For moderate-to-severe PANS, oral or intravenous corticosteroids may be sufficient. However, intravenous immunoglobulin (IVIG) is often the preferred treatment for these patients by most PRC members. For more severe or chronic presentations, prolonged corticosteroid courses (with taper) or repeated high-dose corticosteroids may be indicated. For PANS with extreme and lifethreatening impairment, therapeutic plasma exchange is the first-line therapy given either alone or in combination with IVIG, high-dose intravenous corticosteroids, and/or rituximab.

Conclusions: These recommendations will help guide the use of anti-inflammatory and immunomodulatory therapy in the treatment of PANS.

Keywords: corticosteroids, IVIG, NSAIDs, PANDAS, PANS, plasmapheresis

\section{Introduction}

$\mathbf{T}$ He Diagnosis of Pediatric Acute-onset Neuropsychiatric Syndrome (PANS) is made based on an unusually abrupt onset of obsessive-compulsive (OC) symptoms and/or restricted eating behaviors with at least two comorbid symptoms, including anxiety, emotional lability and/or depression, irritability/oppositionality/ aggression, behavior regression, deterioration in school performance, sensory or motor abnormalities, and somatic symptoms. By definition, PANS is a diagnosis of exclusion, so it is only made in the absence of evidence for other neurological or psychiatric conditions (Swedo et al. 2012). Although a comprehensive diagnostic evaluation should yield a clinical diagnosis, options for treatment are more complex, as PANS is a syndromic illness in which the psychiatric and behavioral abnormalities represent a "final common pathway" for a number of disparate disorders with varied etiologies and disease mechanisms (Swedo et al. 2012; Chang et al. 2015). Despite the heterogeneity of PANS' presentations, neuroinflammation is postulated to play a role in the etiopathogenesis for the majority of PANS cases with some case series documenting immune abnormalities in $>80 \%$ of PANS patients (Frankovich et al. 2015a; Murphy et al. 2015; Swedo et al. 2015). Although not all patients with PANS require immunomodulatory therapies, immunomodulatory interventions are an important consideration in the treatment of acute-onset neuropsychiatric symptoms. When indicated, they should be used in conjunction with other therapies. Conventional psychiatric and behavioral interventions provide direct symptomatic relief and are the mainstay of treatment for the behavioral manifestations of PANS (Thienemann et al. 2017). Targeted antimicrobial therapy also may be useful for children when bacterial infectious triggers have been identified (Cooperstock et al. 2017).

For most autoimmune/inflammatory disorders, the clinical presentation and observed disease course guide treatment choices for each individual patient. The same is true for PANS, which has variable presentations and clinical trajectories. Treatment should be individualized to address the patient's primary symptoms, impairments, and clinical course. Patients with PANS may present with a new-onset or acute flare and follow a relapsing-remitting, chronic-static, or chronic-progressive course. PANS cases with a new-onset or acute flare and documented infectious trigger, such as the subset of cases meeting criteria for Pediatric Autoimmune Neuropsychiatric Disorders Associated with Streptococcal infec- tion (PANDAS), (Swedo et al. 1998) are comparable to Sydenham's chorea (SC). In SC, interventions are targeted toward elimination of the infectious trigger, termination of the postinfectious inflammatory brain process, and prevention of future relapses. PANS cases that follow a relapsing-remitting course may be comparable to other episodic disorders such as multiple sclerosis (MS), Behçet's disease, and asthma (in the opinion of the authors); as in these disorders, treatment focuses on amelioration of the current episode and prevention of future recurrences. The authors believe that PANS patients presenting with severe symptoms and a chronic-static or chronic-progressive course require consideration of more intensive immunomodulatory approaches like those used for neuropsychiatric systemic lupus erythematosus (NPSLE), central nervous system (CNS) vasculitis, autoimmune encephalitis (AE), chronic-progressive MS, chronic-progressive Behçet's disease, and other persistent neuroinflammatory disorders. In these chronic illnesses, as in PANS, infections and other environmental triggers are thought to play a role in provoking an inflammatory brain response, which evolves into a chronic or progressive neuroimmune disorder (Duzova and Bakkaloglu 2008; Costa-Reis et al. 2013; Van Mater 2014; Graus et al. 2016).

In most of the aforementioned inflammatory brain diseases, diagnosis requires evidence for inflammation (peripheral or central). In the case of seronegative $\mathrm{AE}$, evidence of inflammation is typically nonspecific as cerebrospinal fluid (CSF) biomarkers are lacking. Traditional measures of brain inflammation (CSF pleocytosis, protein, and oligoclonal bands) are thought to have limited sensitivity (Dale et al. 2017) and these "false negatives" complicate diagnostic evaluations and treatment decisions. Despite these limitations, it is important to look for such biomarkers, as their presence confirms the presence of CNS inflammation. Additional support for organic cause of the child's mental health deterioration comes from abnormalities of electroencephalography, polysomnography (PSG), and brain imaging studies (magnetic resonance imaging $[\mathrm{MRI}]$ with and without contrast). Finally, findings on the physical examination or results of laboratory studies often reveal evidence of systemic inflammation and/or postinfectious autoimmunity-which may support the use of antiinflammatory and immunomodulatory interventions.

The empiric literature for treatment of PANS is scant, but extensive clinical experience with $>1000$ patients (cumulative total evaluated by PANS Research Consortium [PRC] clinicians) provides strong anecdotal evidence to support the use of anti-inflammatory 
and immunomodulatory therapies in PANS. Significant progress in reducing symptom severity and improving functioning can be accomplished even before evidence emerges from clinical trials, as has been shown for other inflammatory disorders including juvenile idiopathic arthritis, NPSLE (neuropsychiatric lupus), CNS vasculitis, AE, and chronic-progressive Behçet's disease (Hashkes and Laxer 2005; Pohl and Benseler 2013; Van Mater 2014). The immunomodulatory recommendations listed hereunder for severeto-extreme PANS and chronic-progressive PANS are in accord with management strategies used in other pediatric inflammatory brain disorders (Duzova and Bakkaloglu 2008; Pohl and Benseler 2013; Titulaer et al. 2013; Bale 2015; Dale et al. 2017). Particularly apt are the general "principles" of treatment of AE: (1) Patients given immunotherapy do better and relapse less frequently than patients given no treatment. (2) Patients given early treatment do better than patients treated late. (3) When patients fail firstline therapy, second-line therapy improves outcomes and reduces relapses (Nosadini et al. 2015). These "tenets" generally hold true for all autoimmune diseases.

Given the limited precision with which PANS/PANDAS can be diagnosed, and the rudimentary understanding of the pathogenesis, any treatment guidelines cannot be definitive. In this article, we acknowledge these limitations while offering guidelines, developed in the context of current knowledge, to aid care-providers in making treatment decisions.

\section{Rationale for Using Immunomodulatory Therapy in PANS}

Accumulating evidence supports conceptualizing PANS as an immune-mediated brain disease, akin to SC and PANDAS, involving the caudate, putamen, and other basal ganglia structures. Data supporting this model come from epidemiological, clinical, paraclinical, translational, and basic science investigations of PANDAS and SC. In both PANS and PANDAS, clinical evaluations (Frankovich et al. 2015a; Murphy et al. 2015) and research data (Hornig 2013; Hornig and Lipkin 2013; Cutforth et al. 2016) suggest that immune dysfunction may occur at multiple levels: local (targeted) dysfunction relating to cross-reactive antibodies that recognize specific CNS antigens; regional dysfunction relating to inflammation within neuronal tissues or vasculature of the basal ganglia; and systemic abnormalities of cytokine and chemokine production, with resultant disruption of the blood-brain barrier (BBB) and CNS functions (Williams and Swedo 2015). Animal models of PANDAS and SC point to an essential role of the adaptive immune response (autoantibodies and Th17 cells) as possible contributors to disease pathogenesis and neurovascular damage (Hoffman et al. 2004; Yaddanapudi et al. 2010; Brimberg et al. 2012; Cox et al. 2013; Lotan et al. 2014; Cutforth et al. 2016; Dileepan et al. 2016).

Evidence for group A Streptococcus (GAS)-specific crossreactive antibodies having affinity for neuronal components (including receptors) in the basal ganglia has been demonstrated in human and animal studies (Husby et al. 1976; Kirvan et al. 2003, 2006a, 2006b, 2007; Hoffman et al. 2004; Yaddanapudi et al. 2010; Brimberg et al. 2012; Lotan et al. 2014). Sera and immunoglobulin $\mathrm{G}$ (IgG) from SC and PANDAS patients known to bind to components of the GAS cell wall have also been shown to cross-react with components of neurons in the basal ganglia caudate, putamen, and internal segment of the globus pallidus (Kirvan et al. 2006b). Antineuronal IgG antibodies binding to multiple targets, including lysoganglioside, tubulin, and dopamine receptors, have been reported to be elevated in patients with SC and PANDAS compared to controls (Kirvan et al. 2003, 2006a, 2006b, 2007; Cox et al. 2013, 2015). Targeting of such antibodies to dopaminergic neurons in the substantia nigra and ventral tegmental area in the basal ganglia (as well as other cortical neurons) was confirmed in transgenic mice expressing a chimeric antineuronal autoantibody containing $\mathrm{V}_{\mathrm{H}} \pm \mathrm{V}_{\mathrm{L}}$ regions cloned from a patient with SC (Cox et al. 2013).

Binding of cross-reactive antibodies to neuronal cells can activate intracellular signaling pathways, thereby affecting neuronal function. Addition of serum samples from patients with SC or OC and tic disorders to cultured human neuronal cells activated the enzyme calcium calmodulin-dependent protein kinase II (CAMKII) to levels significantly more than both basal cellular levels and levels induced with serum from controls (Cox et al. 2015; Singer et al. 2015). The antineuronal IgGs have the potential to affect neuronal function, as shown by their induction of increased tyrosine hydroxylase (the rate-limiting enzyme in dopamine synthesis) expression in rat brains and increased dopamine release in cultured human neuronal cells (Kirvan et al. 2006a).

Further supporting a role for the adaptive immune response in disease pathogenesis, cross-reactive antibody levels have been found to correlate with disease activity in humans and to directly induce behavioral changes in rodent models. Among SC and PANDAS patients, serum concentrations of cross-reactive antineuronal autoantibodies reacting to lysoganglioside, tubulin, and dopamine receptors (D1 and D2) are increased during acute flares and decreased during periods of symptom remission (Kirvan et al. 2003, 2006a, 2006b, 2007; Brimberg et al. 2012). Rodents peripherally immunized with inactivated GAS antigen, along with agents that help to breach the $\mathrm{BBB}$, demonstrate a range of cognitive and behavioral disturbances including anxiety, repetitive behaviors and others in parallel with production of cross-reactive antibodies (Hoffman et al. 2004; Brimberg et al. 2012). Furthermore, passive transfer of these GASinduced cross-reactive antibodies, through infusion into the basal ganglia of rats or by transfer into the peripheral circulation of mice, resulted in antibody binding to brain targets and produced stereotypies and abnormal behaviors reminiscent of the human disease (Yaddanapudi et al. 2010; Lotan et al. 2014).

In contrast to the aforementioned mouse models, which used killed GAS or GAS components, a novel mouse model used multiple intranasal infections with live GAS. The investigators found that four intranasal GAS infections generated GASspecific Th17 cells that migrated from the nasal-associated lymphoid tissue (the equivalent tissue to human adenoids) into the brain through the olfactory sensory axons. The entry of Th17 cells into the brain was associated with neurovascular damage, including BBB breakdown, neuroinflammation (activation of microglia), and synaptic pathology (loss of excitatory synaptic proteins essential for neurotransmission). This group simultaneously reported that GAS-specific Th17 cells were also present in human tonsils. In this novel mouse model, as previously described in SC, there is evidence of increased levels of cytokines that promote both Th17 responses (interleukin-6 and transforming growth factor beta) and antibody production (Dileepan et al. 2016).

In humans with PANDAS, evidence for regional brain abnormalities comes from neuropsychological evaluations, PSG, and neuroimaging studies demonstrating striatal dysfunction during symptom exacerbations (Williams and Swedo 2015). For example, systematic neuropsychological testing reveals specific deficits of executive function and visuospatial skills, which have been previously shown to reflect basal ganglia dysfunction (Casey et al. 
1994a, 1994b; Hirschtritt et al. 2009; Lewin et al. 2011). PSG evaluation found abnormalities of sleep architecture and the pathological presence of movements during rapid eye movement sleep in 13 of 15 (87\%) PANS patients, which provides direct evidence of neurological disruption (Gaughan et al. 2016). Volumetric MRI analyses of 34 children with PANDAS showed specific increases in the volume of the caudate, putamen, and globus pallidus during acute illness when compared with 82 age-/sex-matched controls (Giedd et al. 2000). Successful treatment with therapeutic plasma exchange (TPE) correlated with normalization of caudate size in one such case (Giedd et al. 1996). Most recently, Chugani and colleagues used positron emission tomography (PET) and the radiopharmaceutical 11C-[R]-PK11195, which binds to activated microglia in the brain, to study 17 children with PANDAS during acute illness. More microglial activation was demonstrated in actively ill PANDAS patients and Tourette syndrome (TS) patients compared with controls. This microglial activation was present in the bilateral caudate and lentiform nuclei in patients with PANDAS and only the caudate in patients with TS. The abnormalities improved in four of five PANDAS subjects treated with intravenous immunoglobulin (IVIG). In the remaining PANDAS case, the initial higher neuroinflammation indications resolved after further IVIG treatment (Kumar et al. 2015).

Further evidence (although indirect) to support immune dysfunction in PANS comes from the high frequency of immune-based conditions (including autoimmune/inflammatory conditions) in patients and their first degree family members (Frankovich et al. 2015a; Murphy et al. 2015). Approximately $71 \%$ of patients' families had one or more first degree relatives with autoimmune/inflammatory disorders (Frankovich et al. 2015a). Further indirect evidence that inflammation can contribute to OC symptoms comes from the frequent association of obsessive-compulsive disorder (OCD) and other neuropsychiatric symptoms in systemic autoimmune diseases like NPSLE, wherein neuropsychiatric symptoms wax and wane in conjunction with systemic inflammation (Slattery et al. 2004; Magro-Checa et al. 2016). Compelling indirect evidence of the link between maternal autoimmunity and tics comes from studies of male offspring with TS and of children with OCD and tics (Murphy et al. 2010; Dalsgaard et al. 2015).

Support for immunomodulation in PANDAS comes from observed benefits of immunomodulatory therapy, with improvements after treatment of PANDAS with IVIG or TPE similar to those reported for SC, Guillain-Barre syndrome, and antibodymediated AE (Garvey et al. 2005; Dalmau et al. 2011; Hughes et al. 2014). IVIG has been shown to have benefits for each of these disorders, although dosing regimens vary and the mechanism of benefit is unknown (Wong and White 2016). A doubleblind, placebo-controlled investigation showed that IVIG and TPE were both effective in reducing OC symptoms in PANDAS patients (by $45 \%$ and $58 \%$, respectively), whereas a placebo infusion had no discernable effect (Perlmutter et al. 1999). The results of the trial were sufficiently robust to convince the American Society of Apheresis to include TPE as a Category I, first-line treatment option for PANDAS, as well as for SC (Weinstein 2008). Subsequent to the controlled trial, several case reports and two case series provide additional support for the therapeutic benefits of TPE and IVIG (Giedd et al. 1996; Tucker et al. 1996; Elia et al. 2005; Garvey et al. 2005; Hachiya et al. 2013; Frankovich et al. 2015b; Gerardi et al. 2015; Kovacevic et al. 2015; Latimer et al. 2015). In contrast, non-PANDAS OCD (Nicolson et al. 2000) and tic disorders (Hoekstra et al. 2004) fail to benefit from TPE and IVIG, respectively.
Although the use of IVIG in the treatment of PANS/PANDAS has received considerable attention in the past decade, no additional placebo-controlled trials were published until this past year (Williams et al. 2016). This trial, conducted jointly between National Institute of Mental Health (NIMH) and the Yale Child Study Center, enrolled rigorously screened subjects and randomized them to receive either IVIG $(n=17)$ or placebo $(n=18)$ in a double-blind study. At 6 weeks, the mean decrease in OCD severity was greater in the IVIG cohort than in placebo, but this difference did not reach statistical significance. Subjects who did not meet "Responder" status in the trial at the 6-week evaluation interval were offered an openlabel IVIG infusion. OCD severity scores for those receiving openlabel IVIG (regardless of whether they had received a placebo or blinded IVIG infusion) decreased roughly $50 \%$ in 6 weeks. Because these improvements were noteworthy only during the open-label phase of the trial, it is not possible to determine how much of this response is because of a positive psychological effect of receiving treatment rather than from the IVIG itself. A number of unanticipated events (multiple subjects acquired new GAS infections during the trial), as well as the study design issues, may have decreased the effect size of the trial. In particular, participants may have over-reported symptom severity in the double-blind portion of the study to increase the possibility of getting open-label IVIG at 6 weeks. Resolution of the conflicting results of the two controlled trials of IVIG will require additional data from carefully controlled clinical trials.

\section{Methods}

The PRC immunomodulatory task force (ITF) is comprised of immunologists, rheumatologists, neurologists, infectious disease experts, general pediatricians, psychiatrists, nurse practitioners, and basic scientists with expertise in neuroimmunology and PANSrelated animal models. The purpose of PRC-ITF was to develop treatment guidelines for the use of anti-inflammatory and immunomodulatory therapies to treat patients with PANS and PANDAS. Preliminary guidelines were created in the Spring of 2014 at the NIMH. Treatment guidelines were refined over the ensuing 2 years over numerous conference calls. These guidelines are based on the expert opinions and clinical experiences of the members of the PRC-ITF and psychiatrists who participated in this process. The article was collaboratively shared and edited as a web-based document wherein all authors incorporated their opinions and experience in using these immunomodulatory therapies to treat patients with PANS. Seven pediatric mental health practitioners (primarily psychiatrists), with expertise in diagnosing and monitoring patients with PANS, were consulted to create categories in disease severity and to critically review final guidelines. All authors played a role in creating and/or forming these guidelines and were also given the opportunity to provide anonymous feedback. The views of all authors were incorporated into the article and all authors gave final approval of these guidelines.

\section{Use of Immune Therapies for PANS}

Immunomodulatory treatment for PANS/PANDAS requires an individually tailored approach, with the intensity of the therapeutic intervention matched to the severity of the child's symptoms and disease trajectory. To reflect this, we have organized guidelines to address treatment of mild, moderate-to-severe, and extreme/ life-threatening clinical presentations. We have made additional recommendations based on disease trajectory, as patients with a single disease episode and relapsing-remitting disease are treated 
differently from those with long-standing chronic-static or chronicprogressive course. Table 1 provides an overview of treatment approaches used for PANS based on disease trajectory.

We want to highlight the importance of mental health providers in both the initial evaluation and ongoing assessments of patients with PANS, as these careful assessments of diseases severity, tra- jectory, and illness course are needed by the medical team to tailor immunomodulatory treatments.

Before initiating immunotherapy, we recommend that clinicians pursue a complete inflammatory brain disease work-up based on published guidelines for AE, CNS vasculitis, NPSLE, acute disseminated encephalomyelitis (ADEM), and Behçet's disease (Van Mater 2014;

Table 1. General Strategies for Management of Pediatric Acute-Onset Neuropsychiatric Syndrome Based on Disease Trajectory

Disease trajectory Recommendations

\section{New-onset or acute flare}

\section{Relapsing-remitting}

\section{Chronic-static or chronic- progressive}

Initial therapy is proposed in the box to the right. Patients with chronic-static or progressive disease may respond to corticosteroids or other induction immunotherapies but then relapse if therapy is stopped. Some patients need repeated doses of steroids and/or other immunotherapies (IVIG or other steroid-sparing agent).
(1) Work-up infections and other causes of acute neuropsychiatric deteriorations per guidelines ${ }^{\mathrm{a}}$ (Van Mater 2014; Chang et al. 2015; Graus et al. 2016; Cooperstock et al. 2017; Dale et al. 2017).

(2) Refer for CBT and provide other supportive therapies (Thienemann et al. 2017).

(3) Consider early use of corticosteroids (oral bursts or IV pulses) to abort or shorten flares (Tables 2 and 3).

(4) Consider high-dose IVIG or other immunomodulatory therapies in moderate-to-severe cases (Tables 2 and 4).

(1)-(4) as above.

(5) Evaluate for possibility of recurrent infections/exposures triggering flares.

(a) If GAS infection is a frequent trigger for relapses, evaluate/treat close contacts and consider prophylaxis according to guidelines (Cooperstock et al. 2017).

(b) Keep in mind that most flares are viral triggers. See (2)-(4) above for treatment of each flare.

(c) Evaluate immune system competency: pursue immunodeficiency work-up if patient has recurrent sinopulmonary disease or fevers per guidelines (Chang et al. 2015). If immunodeficiency is present, IVIG may reduce the number and severity of intercurrent infections (Cooperstock et al. 2017).

(1)-(4) as mentioned.

(5) Pursue immunomodulatory therapies according to symptom categories below:

Mild-to-moderate neuropsychiatric symptoms:

NSAIDs (Table 3).

Oral corticosteroid burst (Table 3) to see whether baseline improves.

Caution: use of combination NSAIDs+corticosteroids may result in gastritis; but these medications can be used safely in tandem.

Mild-to-moderate neuropsychiatric symptoms with no response to NSAIDs and/or short burst of corticosteroids:

(Repeat) oral prednisone \pm prolonged taper (Table 3).

Pulse corticosteroids (oral dexamethasone or IV methylprednisolone) (Table 3).

Moderate-to-severe neuropsychiatric symptoms:

Oral prednisone \pm taper or pulse corticosteroids (Table 3).

High-dose IVIG or other induction steroid-sparing agent (Table 4).

Severe-to-extreme neuropsychiatric symptoms:

Refer to subspecialists for further evaluation for AE, NPSLE, CNS vasculitis, and consideration of using established (published and institutionally based) treatment protocols.

Consider high-dose IV corticosteroids and/or other immunotherapies (Tables 3 and 4).

Refractory disease course (i.e., psychiatric symptoms not responsive to initial immunomodulatory approaches already mentioned and no improvement in neurological signs):

Refer to subspecialist for consideration of additional agents ${ }^{\mathrm{b}}$ and/or combination therapy (up to four immunomodulatory therapies are used simultaneously to treat inflammatory brain diseases; that is, corticosteroids+TPE+IVIG+rituximab).

Consider possibility of injured neurocircuitry and need for shifting to primary rehabilitation mode.

a If the patient meets criteria for another brain inflammatory disease, follow the corresponding treatment guidelines (when published guidelines are not available, use institutionally based guidelines).

${ }^{\mathrm{b}}$ Rituximab, combination immunotherapy, or other aggressive immunomodulation regimens should be managed by clinicians with experience using these therapies, either as the primary prescriber or in close consultation with those managing the patient. There are no reported clinical trials and only limited clinical experience to support these approaches. This is not a definitive treatment algorithm; rather, it is a framework to aid in clinical decisionmaking. Before initiating any of the therapies, clinicians must consider the risk/benefit ratio for their individual patients and provide careful/informed counseling about risk of side effects (see Appendix Tables A1-A3 for detailed discussion of side effects).

$\mathrm{AE}$, autoimmune encephalitis; CBT, cognitive behavioral therapy; CNS, central nervous system; GAS, group A Streptococcus; IV, intravenous; IVIG, intravenous immunoglobulins; NPSLE, neuropsychiatric systemic lupus erythematosus; NSAIDs, nonsteroidal anti-inflammatory drugs; PANS, pediatric acute-onset neuropsychiatric syndrome; TPE, therapeutic plasma exchange. 
Graus et al. 2016; Dale et al. 2017). Clinicians are also urged to ensure completion of infectious disease evaluation and metabolic evaluations. And lastly, clinicians are urged to consider safety precautions outlined in Table 2. These guidelines address initial or induction immunomodulatory therapy (outlined in Tables 3 and 4). Patients with dramatic sustained improvement to immunomodulatory therapy may relapse (especially if long-standing disease is present) when immunomodulation is stopped and/or the effect of the immunomodulation wears off. Chronic suppressive (i.e., maintenance) therapy may be indicated in some cases, but is outside the scope of these guidelines.

\section{Tracking Response to Immune Therapies}

As with any therapeutic intervention, it is important to determine the impact of the treatment. In addition to careful monitoring and charting of the physical and mental status examination, psychometric instruments can help track the disease course. Helpful, reliable, and valid measures include an assessment of overall functioning, such as the Children's Global Assessment Scale, a measure of the most common cardinal symptom, the Children's Yale-Brown ObsessiveCompulsive Scale, and other symptom-specific measures (Clinical Global Impairment Scale, adapted to target symptoms) (Guy 1976; Shaffer et al. 1983; Goodman et al. 1989). Close collaboration between the mental health professional and the clinician managing immune therapies is essential.

\section{Treatment of PANS: Mild Impairment in Functioning Due to PANS Symptoms}

Children with "mild" PANS/PANDAS have clinically significant symptoms and obvious impairments, but these are limited to

Table 2. Considerations Before Pursuing Immunomodulatory Therapy

$\begin{array}{ll}\text { Further work-up Rationales } & \text { Rat }\end{array}$

Lumbar puncture, EEG, MRI, and sleep study (if feasible).

Evaluate for immunodeficiency.

Obtain serum IgA before giving IVIG.

Screen for:

(1) Tuberculosis: PPD or interferon-gamma release assay such as Quantiferon $(\mathrm{R})$ or $\mathrm{T}$ spot assay $(\mathrm{R})$; see age-appropriate guidelines.

(2) Endemic fungi if indicated: For United States, Coccidioidomycosis in Northern California and the Southwest; Blastomyces in the Midwest, South-central, and Southeast; Histoplasma in Central and Eastern states.

(3) Parasitic diseases if indicated: Toxoplasma gondii (worldwide with high prevalence in people with cat interactions and rare meat consumption); Trypanosoma cruzi (Chagas disease endemic in Mexico, Central, and South America).

Hepatitis B serology.

Ensure that the patient's environment (family and/or medical setting) is equipped to handle escalation in psychiatric symptoms.
It is imperative to rule out more specific disorders before starting immunomodulatory therapy (AE, CNS vasculitis, NPSLE, ADEM, infectious encephalitis, etc.) (Graus et al. 2016).

Corticosteroids may mask/treat another brain inflammatory disease and impede accurate diagnosis of another disorder.

Rule out seizure disorders (i.e., ESES) and metabolic/genetic disorders.

Follow established guidelines (institutionally based or published) for evaluation of these other brain diseases.

If mild-to-moderate disease, no memory impairment or encephalopathy, the clinician may choose to defer the LP.

Inflammatory diseases/autoimmunity are more common in patients with immunodeficiency.

Immunodeficiency predisposes to infection and infection may worsen on corticosteroids.

If deficient $(<10 \mathrm{mg} / \mathrm{dL})$, use IgA-depleted IVIG. If possible store a serum sample (one red top) in case further infectious or autoimmune work-up is needed.

Corticosteroids may activate infection.

Rituximab can reactivate hepatitis $B$ virus.

If patient has already had IVIG and has positive hepatitis B serology, check hepatitis B PCR.

Many patients have transient worsening of psychiatric symptoms after corticosteroid burst/pulse and occasionally after initiation of other immunomodulators. If patient has rage/violence, lifethreatening impulsivity, mood instability, suicidality, etc., ensure that the environment can maintain safety in case the patient has escalated behavior.

ADEM, acute disseminated encephalomyelitis; AE, autoimmune encephalitis; CNS, central nervous system; EEG, electroencephalography; ESES, electrical status epilepticus in sleep; IgA, immunoglobulin A; IVIG, intravenous immunoglobulins; LP, lumbar puncture, MRI, magnetic resonance imaging; NPSLE, neuropsychiatric systemic lupus erythematosus; PCR, polymerase chain reaction; PPD, purified protein derivative. 
certain situations and/or settings. OC symptoms might occupy $1-$ 2 hours, occur at intervals throughout the day, and cause minor disruptions at home and in school; however, they do not cause great distress or interfere with overall functioning. In general, the symptom severity falls within the "troubled, but tolerable" range.

The most appropriate therapy (once infection is ruled out) for children in the mild severity range may be "tincture of time" combined with cognitive behavioral therapy and other supportive therapies as described in the psychological/psychiatric guidelines
(Thienemann et al. 2017). PANS/PANDAS is an episodic illness that can have spontaneous symptom remission; therefore, the child is not experiencing significant distress or disruption of daily activities, watchful waiting may be sufficient.

If symptoms continue beyond 2 weeks (especially if the symptoms are worsening and/or impairing function), oral nonsteroidal antiinflammatory drugs (NSAIDs) may be helpful, as tolerated (Table 3 and Appendix Table A1) (Brown et al. 2017b; Spartz et al. 2017). Although the therapeutic mechanisms in PANS are presumed to be

Table 3. General Approach to Using Induction Corticosteroids and/or Nonsteroidal Anti-Inflammatory Drug Therapies in Pediatric Acute-Onset Neuropsychiatric Syndrome/Pediatric Autoimmune Neuropsychiatric Disorders Associated with Streptococcal Infection

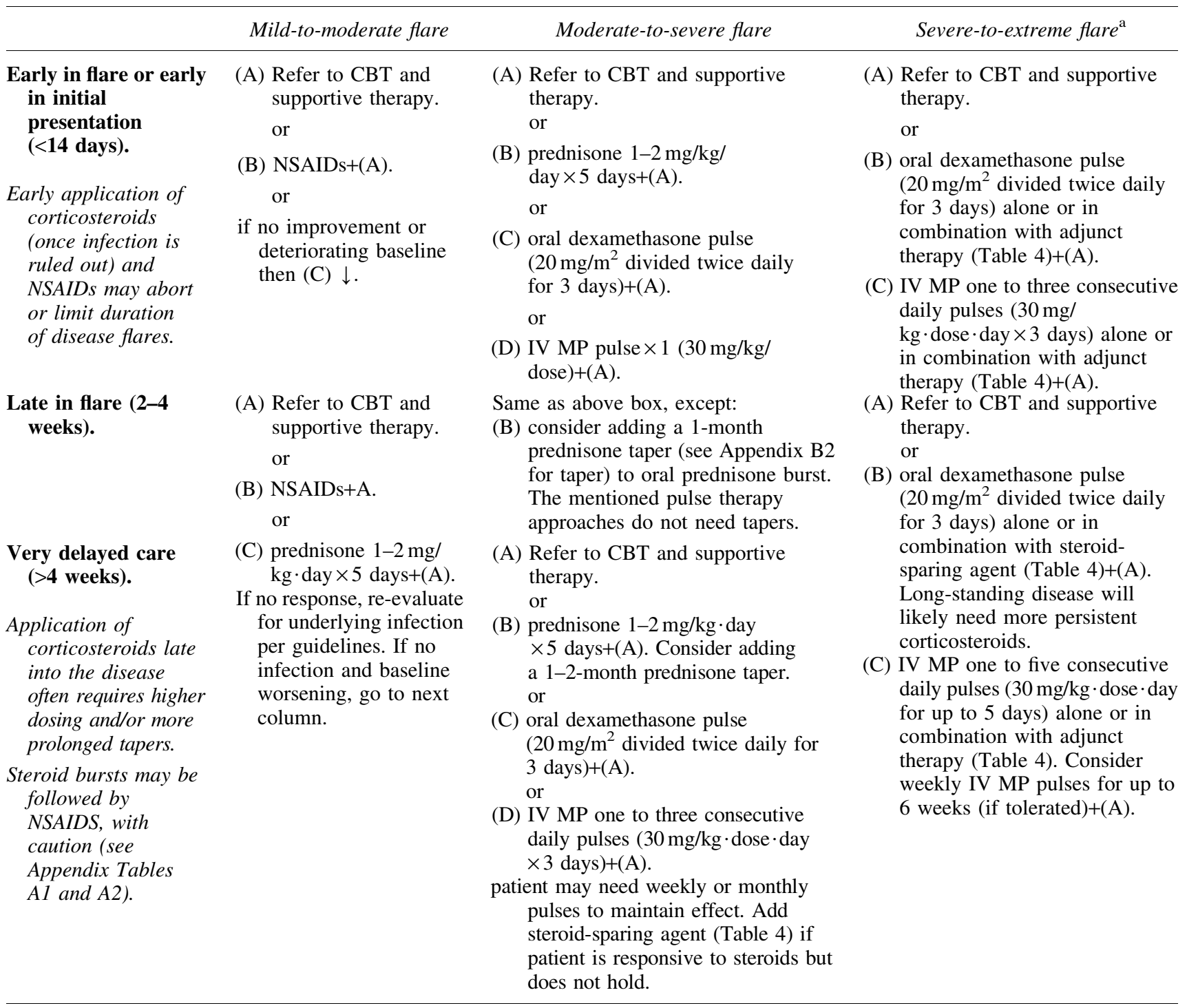

Optimal dosing approaches and utilization of adjunct immunomodulation have not been determined for PANS, but the approaches outlined in this table serve as a starting point for clinicians and academicians who treat patients with PANS and who are planning trials.

Important steroid warning: Most patients have transient worsening of psychiatric symptoms while on corticosteroids. If patient has rage/violence, lifethreatening impulsivity, mood instability, suicidality, etc. and caregivers (including medical personnel) are unable to manage potentiation of these behaviors, give corticosteroids in psychiatric unit or medical-psychiatric unit or bypass corticosteroids and go straight to IVIG or other steroid-sparing agent (Table 4).

If no response to initial corticosteroid burst/pulse or relapse after steroid burst/pulse, consider reassessing for underlying infection per guidelines (Chang et al. 2015; Cooperstock et al. 2017) with attention to the possibility of sinusitis or close contact with GAS or asymptomatic acquisition of GAS. If no infection, repeat steroid bursts/pulses and/or give corticosteroid sparing agent (Table 4).

For details regarding side effects and dosing of NSAIDs and corticosteroids (including maximum dosing) go to Appendix Tables A1 and A2.

${ }^{\mathrm{a}}$ If patient meets criteria for another brain inflammatory disease, use said treatment protocol.

AE, autoimmune encephalitis; CBT, cognitive behavioral therapy; GAS, group A Streptococcus; IV, intravenous; IVIG, intravenous immunoglobulins; MP, methylprednisolone; NSAIDs, nonsteroidal anti-inflammatory drugs; PANS, pediatric acute-onset neuropsychiatric syndrome. 
the anti-inflammatory properties of the NSAIDs, it is interesting that these medications have reported benefits in other psychiatric conditions. For example, the use of celecoxib was helpful in reducing OCD symptoms in adult participants of two clinical studies (Sayyah et al. 2011; Shalbafan et al. 2015). Clinical trials have also shown benefit of NSAIDs in schizophrenia, bipolar disorder, and depression (Müller et al. 2004; Abbasi et al. 2012; Arabzadeh et al. 2015). In a recent retrospective study of consecutive patients trialed on NSAIDs, approximately one-third of the patients were reported to have improvement in some or all PANS symptoms and an additional one-third of the patients had deterioration after the NSAID was discontinued, suggesting possible efficacy (Spartz et al. 2017). In another retrospective study, NSAID use was associated with shorter duration of PANS flares compared with untreated flares (Brown et al. 2017b). Based on our clinical experience, NSAID trials in PANS patients should be 6 weeks long. The effect of NSAIDs can wane over time, so it is important to conduct periodic discontinuation trials, closely monitoring symptoms during the withdrawal period. If discontinuation of the NSAIDs results in recrudescence of symptoms, the medications can be restarted and continued for another 6 weeks or longer. Some patients have remained on NSAIDs chronically when continued benefit is demonstrated with on/off trials (Spartz et al. 2017).

It is the authors' experience that NSAIDs can be used safely in the long term if standard precautions are taken (Appendix Table A1). NSAIDs should be used with caution in the setting of restricted fluid intake (because of concern for renal toxicity in the setting of dehydration) and swallowing difficulties (because of concern for esophageal erosions) (Appendix Table A1). In some cases, NSAIDs can contribute to gastritis, gastroesophageal reflux disease, esophageal erosion, decreased appetite, constipation, diarrhea, and nausea (Ruperto et al. 2005; Sobel et al. 2014). Other possible side effects include hypertension, skin fragility (pseudoporphyria), sun sensitivity,

Table 4. Corticosteroid-Sparing Agents (Therapies Used in Conjunction with Steroids or to Replace Corticosteroids) That Have Been Used in Pediatric Acute-Onset Neuropsychiatric Syndrome/Pediatric Autoimmune Neuropsychiatric Disorders Associated with Streptococcal infection

\begin{tabular}{|c|c|c|c|}
\hline & $I V I G$ & $T P E$ & Rituximab or $M M F^{\mathrm{a}}$ \\
\hline New onset. & $\begin{array}{l}\text { One to six monthly courses of } \\
\text { IVIG in moderate-to-severe } \\
\text { disease or in severe-to-extreme } \\
\text { if TPE not available. }\end{array}$ & $\begin{array}{l}\text { Use in severe-to-extreme cases if } \\
\text { patient has life-threatening } \\
\text { disease. }\end{array}$ & $\begin{array}{l}\text { Patient has moderate-to-extreme } \\
\text { impairment. } \\
\text { and } \\
\text { patient has proven (documented by menta } \\
\text { health professional) responsiveness to } \\
\text { corticosteroids, IVIG, or TPE. } \\
\text { and } \\
\text { patient has evidence of inflammation/ } \\
\text { autoimmunity and objective signs of } \\
\text { organic brain disease. }\end{array}$ \\
\hline $\begin{array}{l}\text { Relapsing-remitting } \\
\text { course. }\end{array}$ & $\begin{array}{l}\text { Consider repeated dosing } \\
\text { of IVIG if patient meets } \\
\text { criteria for an } \\
\text { immunodeficiency syndrome. }\end{array}$ & $\begin{array}{l}\text { Not indicated unless patient is in } \\
\text { a severe-to-extreme flare. }\end{array}$ & $\begin{array}{l}\text { Consider use if patient has a deteriorating } \\
\text { baseline (i.e., each flare leaves the } \\
\text { patient with permanent deficits) or } \\
\text { frequent relapses. } \\
\text { and } \\
\text { patient has proven responsiveness to } \\
\text { corticosteroids, IVIG, or TPE. } \\
\text { and } \\
\text { patient has evidence of inflammation/ } \\
\text { autoimmunity and objective signs of } \\
\text { organic brain disease. }\end{array}$ \\
\hline $\begin{array}{l}\text { Very delayed care, } \\
\text { chronic-static, } \\
\text { or chronic- } \\
\text { progressive } \\
\text { course. }\end{array}$ & $\begin{array}{l}\text { Trial of IVIG. If patient } \\
\text { responds, then symptoms } \\
\text { recrudesce then patient is } \\
\text { deemed immune therapy } \\
\text { responsive, thus consider (A), } \\
\text { (B), or (C). } \\
\text { (A) Monthly IVIG until patient } \\
\text { is no longer having period of } \\
\text { improvement after IVIG and } \\
\text { recrudescence as IVIG effect } \\
\text { wanes. } \\
\text { (B) Rituximab, MMF, etc. } \\
\text { (C) (A)+(B). }\end{array}$ & $\begin{array}{l}\text { Response to TPE may be } \\
\text { transient. Consider } \\
\text { introduction of rituximab or } \\
\text { MMF if there is evidence of } \\
\text { autoimmunity. }\end{array}$ & $\begin{array}{l}\text { Patient has moderate-to-extreme } \\
\text { impairment. } \\
\text { and } \\
\text { patient has proven responsiveness to } \\
\text { corticosteroids, IVIG, or TPE. } \\
\text { and } \\
\text { patient has evidence of inflammation/ } \\
\text { autoimmunity and objective signs of } \\
\text { organic brain disease. }\end{array}$ \\
\hline
\end{tabular}

Goal is to achieve remission with minimal corticosteroids.

${ }^{a}$ Rituximab and MMF are generally used when the patient has demonstrated steroid/IVIG responsiveness, but the patient is steroid/IVIG dependent and there is a chronic course. Duration of therapy needed is unknown. For other inflammatory brain diseases, MMF is used for up to 5 years and rituximab is used for 1-3 years \pm additional years of MMF.

IVIG, intravenous immunoglobulins; MMF, mycophenylate mofetil; PANS, pediatric acute-onset neuropsychiatric syndrome; TPE, therapeutic plasma exchange. 
rectal hemorrhage, epistaxis, hematoma, and hematuria. NSAIDs should not be used in the setting of ethanol use, especially if there is binge drinking. In two recent PANS studies, all side effects were selflimited and there were no significant (injurious) toxicities, including esophageal erosions, liver toxicity, and renal toxicity (Brown et al. 2017b; Spartz et al. 2017).

Brief courses of oral corticosteroids are another option for mild-tomoderate PANS, as the risks are minimal and the benefits can be dramatic, particularly if given within 1-3 days of symptom onset. However, if the child has mood instability, including rage or aggression, corticosteroids should be used with caution as they may exacerbate these symptoms. As with asthma, oral corticosteroid bursts (prednisone $1-2 \mathrm{mg} / \mathrm{kg} / \mathrm{day}$; given as single dose in morning or divided twice daily, maximum $60-120 \mathrm{mg}$ daily, for 5 days) may hasten recovery and minimize residual symptoms. In a recent retrospective study of patients meeting PANS or PANDAS criteria, flares treated with corticosteroids lasted on average 6.4 weeks and flares not treated with corticosteroids lasted on average 11.4 weeks (multilevel model, $p<0.01$ ) (Brown et al. 2017a). In this study, use of steroids in the setting of an infectious illness had less impact on neuropsychiatric symptoms (Brown et al. 2017a) and thus, these patients may need a repeat steroid burst or delay in the initial steroid burst.

Patients who improve with the corticosteroids but then relapse as the steroid effect wanes may benefit from an additional corticosteroid burst with or without a taper (see Appendix Table A2 for an example of burst and taper). Patients in a prolonged flare may also have improvement in their function after a course of corticosteroids. A slow taper will incur more side effects (Appendix Table A2) and should be considered only if symptoms are impairing enough to justify the side effects. Refer to Table 2 for the medical evaluation, which must be completed before initiating treatment with corticosteroids. See Table 3 for strategies regarding use of corticosteroids in PANS based on clinical severity and disease trajectory. See Appendix Table A2 for an outline of risks associated with corticosteroids.

There is not enough data to reconcile the strategies of "tincture of time" for self-recovery versus "early aggressive therapy," which is the approach used in other brain inflammatory diseases (Van Mater 2014; Nosadini et al. 2015; Dale et al. 2017). If a patient has a history of flares that do not self-resolve, then strongly consider early use of corticosteroids followed by NSAIDs (Brown et al. 2017a, 2017b; Spartz et al. 2017).

Behavioral side effects of corticosteroids are always of concern. Not all patients are candidates for corticosteroid therapy as it may temporarily worsen OC symptoms, anxiety, rage, irritability/agitation, depression, emotional lability, and insomnia. Although these symptoms can be managed with appropriate psychotherapeutic and behavioral interventions, the clinician must use caution in patients whose PANS symptoms include aggression, rage, or impulsivity. For most patients with clinically significant symptoms, the risk/benefit ratio favors use of corticosteroids, as the temporary worsening of neuropsychiatric symptoms is offset by the potential benefits of returning the child to baseline functioning more quickly. Importantly, short courses of corticosteroids, especially at low doses, are rarely associated with long-term side effects (Da Silva et al. 2006).

\section{Treatment of PANS: Moderate-to-Severe Impairment in Functioning Due to PANS Symptoms}

Children with moderate-to-severe symptoms of PANS/ PANDAS have symptoms that are distressing and impairing, but not overwhelming or incapacitating. Their OC symptoms may occupy $50 \%-70 \%$ of their waking hours. The OC symptoms along with other PANS symptoms cause significant interference with daily activities, but the children have at least short periods of relief. Their intake of food or fluid may be reduced, but they are not medically compromised. Rituals or separation anxiety may prevent the children from attending school, but they are able to leave the house with a loved one or have friends visit for brief periods. Ancillary symptoms are similarly impairing and might include embarrassing, painful, or disruptive adventitious movements, pollakiuria (urinary frequency), sleep disruptions, and cognitive impairment, leading to school difficulties including writing difficulties, loss of math and reading skills, reduced processing speed, and memory impairment. Emotional lability, irritability, and aggression are often the most problematic symptoms for children with moderate-to-severe symptoms of PANS. These patients may present to emergency departments because of rapid changes in their behavior and function. If a child's behavior has escalated to the point wherein he is a danger to himself or others, he would be considered to have "extreme or life-threatening" symptoms, as discussed hereunder.

Immunomodulatory therapy is typically warranted for PANS cases with moderate-to-severe impairment. Oral corticosteroids may be sufficient, particularly if given within a few days of symptom onset. In the aforementioned retrospective study, earlier steroid use was associated with earlier time to recovery from flare (Brown et al. 2017a). For more severe or chronic symptoms, a prolonged corticosteroids course (with taper) or corticosteroid pulses may be indicated. High-dose IV methylprednisolone (MP) pulses (IV MP $15-30 \mathrm{mg} / \mathrm{kg}$, maximum dose $1 \mathrm{~g}$, daily for 35 days) are more likely to result in a robust and rapid change in symptom severity, leading to its selection as initial therapy for most children and adults with autoimmune encephalitides such as anti$\mathrm{N}$-methyl-D-aspartate receptor encephalitis (NMDAR) (Dalmau et al. 2011). Some PRC-ITF members have adopted the protocol of high-dose pulsatile oral dexamethasone (dexamethasone $20 \mathrm{mg} / \mathrm{m}^{2}$ divided twice daily for 3 days), which is used in treating another pediatric autoimmune CNS disorder, opsoclonus-myoclonus syndrome (Rostasy et al. 2006). In SC, higher doses of corticosteroids administered for a longer duration resulted in greater symptom reduction and shortened disease duration (Barash et al. 2005; Paz et al. 2006; Walker et al. 2007). Similarly, in PANS and PANDAS, longer steroid courses resulted in a longer duration of neuropsychiatric symptom improvement (Brown et al. 2017a).

However, it is important to keep in mind that high doses and prolonged use of corticosteroids are associated with more risks, including permanent injury to eyes (cataracts and glaucoma) and bones (avascular necrosis) and escalated psychiatric symptoms. Furthermore, corticosteroids should not be used when there is the possibility that symptoms are due to infection, metabolic disturbance, or neurodegenerative disorder (Vernino et al. 2007). See Appendix Table A2 for corticosteroid dosing regimens and discussion of associated risks. Careful assessment of the risks and potential benefits of steroid use must be done for each PANS case, especially because psychiatric symptoms may escalate initially and the patient could develop life-threatening behaviors. Table 3 provides a summary of the use of corticosteroids in moderate-toseverely ill patients.

In general, empiric use of corticosteroids in patients with unexplained new-onset neuropsychiatric deterioration is becoming the standard of care, once infections, metabolic disturbances, and neurodegenerative disorders are excluded (Vernino et al. 2007; Dalmau et al. 2011; Nosadini et al. 2015). To diagnose steroid- 
responsive inflammatory brain disease, the clinical response to steroid administration should be unequivocal and persist for a week or more beyond the time of treatment (Vernino et al. 2007). However, patients with long-standing chronic-static or chronic-progressive disease often have diminished responses to corticosteroids and may require many months of combination immunomodulatory therapy before significant treatment gains are seen.

Because improvement with corticosteroids often wants after cessation of corticosteroids therapy, and long-term corticosteroid use may be associated with permanent toxicities (cataracts, bone infarcts, diabetes, hypertension, weight gain, etc.), steroid sparing immunomodulatory agents are often needed. For this reason, IVIG alone or in combination with corticosteroids is often preferred for treatment of moderate-to-severe PANS. The recommended induction dose of IVIG is $1.5-2 \mathrm{~g} / \mathrm{kg}$ (maximum dose is typically $70 \mathrm{~g}$, but on rare occasions up to $120 \mathrm{~g}$ has been used by PRC members) and 1-2 g/kg for second and subsequent dosing. This induction dose is equivalent to that used for other pediatric inflammatory disorders, including, but not limited to $\mathrm{AE}$, Kawasaki disease, juvenile dermatomyositis, idiopathic thrombocytopenic purpura, and Guillain-Barre syndrome (Hughes et al. 2014; Nosadini et al. 2016). One clinical case series of 12 youth with PANDAS reported benefits of a $1.5 \mathrm{~g} / \mathrm{kg}$ total dose (Kovacevic et al. 2015). The dose and timing of IVIG administration should be determined in collaboration with clinicians and pharmacists experienced in its use. Controlled trials only have evaluated single courses of IVIG, but the authors' unpublished experiences suggest that one to three repeated doses of IVIG may be appropriate for children who have a good initial response to IVIG, but then relapse as the IVIG is cleared from circulation. Of note, the response to IVIG is often delayed by 2-3 weeks, and some symptom domains may show more improvements than others. In such patients, additional improvements may be gained with each cycle of IVIG. Monthly IVIG has been used in a number of other brain inflammatory diseases, including relapsing-remitting MS, NPSLE, AE, and others (Fazekas et al. 1997; Leach et al. 1999; Zandman-Goddard et al. 2012). However, repeated doses of IVIG have not been systematically assessed for PANS. It is the authors' opinion that the burden of monthly IVIG (beyond 3-6 monthly doses) may outweigh the benefit in many cases. The burden-to-benefit ratio has to be considered critically for each individual patient until more data are available to give direction on this approach.

Although high-dose IVIG can be given in one day (as is the case with Kawasaki disease), it is the authors' experience that patients with PANS do not tolerate this high rate of infusion, primarily because of severe postinfusion headaches, many of which are accompanied by meningeal signs and likely attributable to aseptic meningitis. Severe headaches (including migraines) and aseptic meningitis are among the most commonly described side effects of IVIG, with rates of $2 \%-75 \%$ and $1 \%-11 \%$ reported, respectively (Pierce and Jain 2003; Orange et al. 2006; Bharath et al. 2015; Thornby et al. 2015; Cherin et al. 2016). Among patients receiving immunomodulatory doses of IVIG $(2 \mathrm{~g} / \mathrm{kg})$, those with a history of headaches are at higher risk for IVIG-induced headaches and/or aseptic meningitis. Typically headaches will develop within six hours of infusion but may start as late as 72 hours after the infusion (Rappold et al. 2015; Cherin et al. 2016). Headaches typically last 3-7 days in patients with PANS (authors' experience).

Some centers have divided the total IVIG dose into as many as five daily doses given on five consecutive days with a low rate of infusion for patients who could not otherwise tolerate the treatment because of severe nausea, vomiting, and/or headaches. Although this approach may be necessary in some individuals, the efficacy is unknown. A clinical trial in children with Kawasaki disease found that IVIG had added anti-inflammatory effects if the dose $(2 \mathrm{~g} / \mathrm{kg})$ is given for 10 hours on a single day compared with four smaller daily doses $(400 \mathrm{mg} / \mathrm{kg}$ ) (Newburger et al. 1991).

The authors recommend the following strategies to help mitigate and/or manage post-IVIG headaches: (1) Divide the total IVIG dose into at least two daily doses given on two consecutive days; (2) Employ aggressive hydration (before, during, and after IVIG); (3) Use anti-inflammatory medications (either regular dosing of NSAIDs or a corticosteroid burst); (4) Consider regular dosing of antinausea medications (may be contraindicated for patients with dystonic reactions or chronic constipation); (5) Be prepared that some patients may require opiate pain medications to manage severe headaches (again, use with caution in patients with constipation or on sedating medications).

Most other side effects of IVIG are self-limited or may be prevented with premedication; however, rare side effects, including anaphylaxis, thromboembolic events, hemolytic reactions, and renal failure, among others, may cause significant mortality and/or morbidity (Pierce and Jain 2003; Orange et al. 2006; Cherin et al. 2016). Patients with restricted eating and/or restricted fluid intake are especially vulnerable to headaches and hyperviscosity issues; these patients require close monitoring after IVIG and may require additional boluses of IV fluids. Transmission of occult infections is an additional risk of IVIG, as it is a pooled human donor product. The severity of PANS symptoms must outweigh all potential risks (See Appendix Table A3 for a more detailed discussion on side effects of IVIG and managing IVIG in patients with PANS).

According to the authors' experience, patients receiving early treatment of PANS usually require only one, two, or three courses of high-dose IVIG. However, long-standing disease takes more time and effort to improve. This is true for other inflammatory disorders such as arthritis, systemic lupus erythematosus (SLE), asthma, and $\mathrm{AE}$, in which long-standing untreated or undertreated disease has a worse prognosis and requires considerably more aggressive treatment than disease treated early (Wallace et al. 2014; Nosadini et al. 2015; Dale et al. 2017).

Some PRC-ITF members have successfully employed monthly high-dose IVIG to treat long-standing PANS symptoms. However, the authors recommend that repeated doses of IVIG be used only for patients who clearly benefit from each IVIG infusion and then experience a recrudescence of symptoms when the IVIG effect starts to wane (often around 3-6 weeks). Spacing out and eventually discontinuing IVIG infusions should occur when there is no longer improvement following IVIG. At that point, time intervals between IVIG infusions should be increased, and if there is no further recrudescence of symptoms, IVIG should be discontinued. In lieu of repeated IVIG infusions, some of the PRC-ITF members add secondary immunomodulatory agents. In children who have an incomplete response to IVIG or have significant flares while on IVIG, corticosteroids and other immunosuppressive agents have been used in addition to the IVIG (when benefits outweigh the risks).

In some clinical settings, arranging for IVIG infusion may take a significant amount of time. In select cases, PRC members pursue oral or IV corticosteroids (after active infection is ruled out or treated) while waiting for IVIG to be approved. Based on authors' experience, a positive response to corticosteroids is a good indication that further immunomodulatory therapy will be helpful, but a tepid response to low-dose oral prednisone burst $(1-2 \mathrm{mg} / \mathrm{kg}$ for five days) is not a predictor of IVIG or second-line failure. 
Treatment of PANS: Extreme or Life-Threatening Impairment of Functioning Due to PANS Symptoms

Children with extremely severe symptoms of PANS suffer from OC symptoms that occupy $90 \%-100 \%$ of their waking hours and experience profound distress from separation anxiety, generalized anxiety, depression, and emotional lability. Children with restricted food and fluid intake (usually because of fears of contamination, choking, vomiting, etc.) can develop dehydration, significant weight loss ( $>10 \%$ of body weight), and vital sign instability (Toufexis et al. 2015). In these extreme cases, comorbid symptoms are also incapacitating and may include severe behavioral regressions, cognitive dysfunctions, memory impairment, social withdrawal, extreme irritability, aggression, emotional lability, violent imagery, hallucinations and/or delusions, sensory amplification, movement disorders (choreatic, dystonic, and stereotypic), and tics. Some children present with severe difficulty in walking and/or sitting without support. Not only are the symptoms extremely distressing to the child and his or her caregivers, but they may prevent him or her from leaving the house, attending school, and accomplishing activities of daily living (e.g., eating, showering, or toileting). Of note, the combination of escalated impulsivity, behavioral regression, mood lability, and irrational fears can lead to life-threatening impulsive actions. In such cases, the first goal of therapy must be to ensure everyone's safety, either with 24-hour monitoring at home or in the hospital (Thienemann et al. 2017). Inpatient psychiatric hospitalization is often the safest option, but severe separation anxiety may require accommodations for a parent to stay with the child.

If available, TPE is first-line therapy for extreme and lifethreatening PANS, as it has been shown to produce the greatest degree of symptom improvement for the shortest period in PANDAS, NPSLE, and anti-NMDAR encephalitis (Perlmutter et al. 1999; Neuwelt 2003; Dalmau et al. 2011). Five single-volume exchanges for 7-10 days are considered optimal (Perlmutter et al. 1999; Szczepiorkowski et al. 2007), although a recent case series reported benefits of a shorter course of only three to four treatments (1.5 volume exchange during each TPE treatment) (Latimer et al. 2015). Details of the five-exchange treatment regimen are available upon request (Swedo, NIMH). TPE will cause hypogammaglobulinemia, so clinicians might consider adding IVIG as adjunctive therapy (at anti-inflammatory doses already discussed). Complications of TPE include line infection, thrombosis, anemia, syncope, pseudoseizures, and pain amplification. The last three symptoms typically occur in the hours to days after cessation of TPE.

In chronic autoimmune disorders (SLE, granulomatosis with polyangiitis, microscopic polyangiitis, etc.), TPE alone is not sufficient to provide lasting symptomatic improvements (Jones et al. 1981). Thus, in these disorders, TPE is generally used in conjunction with a maintenance immunosuppression regimen such as rituximab. Experience in PANS is limited, but suggests that TPE alone may produce only temporary improvements in patients with chronic-static or chronic-progressive illness. Adjunctive immunomodulation may be warranted in such cases.

If TPE is not available, then the combination of IV MP pulses and IVIG is a reasonable alternative. Rituximab, mycophenolate mofetil (MMF), and other immunomodulatory agents should be considered, in cases with evidence of neuroinflammation or autoimmunity (Chang et al. 2015) or in cases who have previously demonstrated sustained improvement after IV MP or IVIG but then relapse. Only clinicians experienced in the use of these therapies should use them. Also, the child must have an established rela- tionship with a psychiatrist who is prepared to manage emerging psychiatric symptoms, particularly during induction therapy. PRC members have reported initial worsening of psychiatric symptoms during the induction with corticosteroids, MMF, and rituximab. Rarely, new-onset psychosis has been observed with all three of these agents, which resolved after discontinuation of the inciting medication.

\section{Chronic-Static or Deteriorating Course of PANS IIIness}

At this time, it is not possible to predict the course of illness in patients with PANS. Many children will remit after a single course of immunotherapy and subsequent exacerbations can be forestalled by antibiotic prophylaxis and/or brief courses of corticosteroids applied early in the flares. Others have a persistent or deteriorating course and require ongoing or more intensive treatments. In addition to therapies that remove pathogenic autoantibodies, attention should be paid to eradicating their production. Antibiotics, or even surgery, can be effective if the presumptive antigenic source can be targeted (e.g., chronic sinusitis, enhancing sinus cyst, tonsillar abscess, or microabscesses). A small number of reports suggest that tonsillectomy and adenoidectomy may be helpful in PANS, perhaps by removing occult infections that are triggering symptom exacerbations (Heubi and Shott 2003; Fusco et al. 2010; Alexander et al. 2011; Demesh et al. 2015). However, systematic comparisons of PANS/PANDAS children who had a tonsillectomy/adenoidectomy with those who had not failed to detect any benefits of the surgery (Murphy et al. 2013; Pavone et al. 2014). Thus, the PRC is not recommending tonsillectomy or adenoidectomy as a routine intervention for PANDAS or PANS and supports use of the procedures only when indicated per current surgical guidelines (Baugh et al. 2011).

For some children with PANS, the clinical course suggests that a temporary postinfectious pathological immune response has evolved to become a chronic autoimmune condition, most likely because of loss of tolerance and ongoing $\mathrm{T}$ cell and/or B cell activity against self-antigens. Such cases may require more aggressive and persistent immunomodulatory therapies with demonstrated effectiveness against other brain inflammatory disorders. These might include: (1) repeated pulsing of high-dose IV MP and/or a more prolonged course of oral corticosteroids, (2) rituximab, (3) MMF, (4) cyclophosphamide, and (5) other treatments used to treat inflammatory brain disease (Hahn et al. 2001, 2012; Dalmau et al. 2011; Dale et al. 2017). Recommendations for use of these interventions are beyond the scope of these guidelines and patients should be referred to centers specializing in the treatment of neuroimmune disorders.

\section{Refractory Disease Course}

One must consider the possibility of injured neurocircuitry and the need to shift to primary rehabilitation mode in patients whose psychiatric symptoms are not (or are no longer) responsive to the mentioned immunomodulatory approaches (especially those who have no response to high-dose MP pulses).

\section{Other Considerations}

A recent clinical trial in PANS demonstrated efficacy of azithromycin over placebo (Murphy et al. 2017). PRC members suspect that the mechanism of action of azithromycin in PANS may, in part, be related to its anti-inflammatory properties (Sharma et al. 
2007; Murphy et al. 2008; Altenburg et al. 2010a, 2010b; Obregon et al. 2012).

\section{Conclusions}

Choosing the optimal immunomodulatory treatment pathway for the patient with PANS/PANDAS requires consideration of the disease severity and trajectory, as well as an understanding of the PANS symptoms in the broader context of infection and inflammatory disease. The general "principles" used to treat other brain inflammatory diseases (AE, NPSLE, etc.) likely apply to PANS (especially those presenting with severe symptoms): (1) Patients given immunotherapy do better and relapse less frequently than patients given no treatment; (2) Patients given early treatment do better; (3) When patients fail first-line therapy, second-line therapy improves outcomes and reduces relapses (Titulaer et al. 2013; Nosadini et al. 2015). Immunomodulatory therapy should be considered early, because NSAIDs or a short course of oral corticosteroids may be sufficient for symptom remission in recent-onset cases, whereas those with long-standing symptoms often require more intensive and prolonged immunotherapeutic interventions.

\section{Clinical Significance}

Until further research informs clinicians about the effectiveness of immunomodulatory therapy for PANS and PANDAS, current literature and clinical experience must guide clinicians treating these children. This article fills the gap between evidence-based treatments and current knowledge by conveying guidelines from a panel of experts for use of immunomodulatory therapy in children with PANS and PANDAS

\section{Acknowledgments}

Dr. Caroline Gromark, MD (Psychiatrist and Director of the PANS Clinic, Karolinska Institute, Stockholm, Sweden) is thanked for their critical review of these guidelines. This work was supported (in part) by the Intramural Research Program of the NIMH and the PANDAS Physician Network.

\section{Disclosures}

R.C.D. has received speaker honoraria from Biogen Idec, Bristol-Myers-Squibb, is an editorial advisory board member for MSARD, an editorial board member for Neurology: Neuroimmunology and Neuroinflammation and European Journal of Paediatric Neurology, received publishing royalties from Biogen and Bristol-Myers-Squibb, and research support from NHMRC, Multiple Sclerosis Research Australia. M.C. is Chief Scientific Officer at Moleculera Labs, a company offering antineuronal autoantibody testing for neuropsychiatric and movement disorders. R.B. has received speaking fees from Medac (less than \$5000). G.B. has received research support from NIMH, National Science Foundation, and F. Hoffman-La Roche. K.C. (Disclosures 2014) is an unpaid consultant for GSK, Lilly, and BMS. $\mathrm{He}$ is on the DSMB for Sunovion. In the past 2 years, he has received research support from GSK and Merck. D.G. reports grant support from NIH and book honorarium from the American Academy of Child and Adolescent Psychiatry, speaking honoraria for Advanced Institute lectures from the American Academy of Child and Adolescent Psychiatry and Massachusetts General Hospital Psychiatry Academy in educational programs supported through independent medical education grants from pharmaceu- tical companies. Current funding is from Neurocrine Bioscience for clinical trial of Tourette's disorder. Lifetime funding includes support from the Obsessive Compulsive Disorder Foundation, The Tourette Syndrome Association, The McIngvale Family Foundation, Eli Lilly, Pfizer, and Glaxo Smith Kline. J.L. reported receiving grant support from the National Institutes of Health, the UBS Optimus Foundation, and the Open Road Alliance. He serves pro bono on the advisory boards of the Brain and Behavior Research Foundation, Fondazione Child, the European Multicentre Tics in Children Studies, How I Decide, and Empathy for Peace. He receives book royalties from John Wiley and Sons, McGraw Hill, and Oxford University Press. T.M. has received research support from the following: NIH/NIMH: 1RO1MH093381-01A1, 1R21MH087849-01A1, 1R01HD080096-01A1, R34; Centers for Disease Control and Prevention: 5 U01DD000509-02, International OCD Foundation; AstraZeneca Pharmaceuticals; Sunovion Pharmaceuticals, Inc.; F. Hoffmann-LaRoche Ltd.; PANDAS Network; Neurocrine Biosciences, Inc.; Auspex Pharmaceuticals; Teva Pharmaceuticals; Shire Pharmaceuticals; Pfizer, Inc.; Massachusetts General Hospital; Psyadon Pharmaceuticals, Inc.; and Forest Research Institute, Inc. She has received travel support from the Tourette Syndrome Association and honoraria from grand rounds lectures. She also receives book royalties from Lawrence Erlbaum, Inc. and Taylor \& Francis. All other authors have no competing financial interests.

\section{References}

Abbasi SH, Hosseini F, Modabbernia A, Ashrafi M, Akhondzadeh S: Effect of celecoxib add-on treatment on symptoms and serum IL-6 concentrations in patients with major depressive disorder: Randomized double-blind placebo-controlled study. J Affect Disord 141:308-314, 2012.

Alexander AA, Patel NJ, Southammakosane CA, Mortensen MM: Pediatric autoimmune neuropsychiatric disorders associated with streptococcal infections (PANDAS): An indication for tonsillectomy. Int J Pediatr Otorhinolaryngol 75:872-873, 2011.

Altenburg J, De Graaff CS, Van Der Werf TS, Boersma WG: Immunomodulatory effects of macrolide antibiotics - Part 1: Biological mechanisms. Respiration 81:67-74, 2010a.

Altenburg J, De Graaff CS, Van Der Werf TS, Boersma WG: Immunomodulatory effects of macrolide antibiotics - Part 2: Advantages and disadvantages of long-term, low-dose macrolide therapy. Respiration 81:75-87, 2010b.

Arabzadeh S, Ameli N, Zeinoddini A, Rezaei F, Farokhnia M, Mohammadinejad P, Ghaleiha A, Akhondzadeh S: Celecoxib adjunctive therapy for acute bipolar mania: A randomized, double-blind, placebo-controlled trial. Bipolar Disord 17:606-614, 2015.

Bale JF, Jr: Virus and immune-mediated encephalitides: epidemiology, diagnosis, treatment, and prevention. Pediatr Neurol 53:3$12,2015$.

Barash J, Margalith D, Matitiau A: Corticosteroid treatment in patients with Sydenham's chorea. Pediatr Neurol 32:205-207, 2005.

Baugh RF, Archer SM, Mitchell RB, Rosenfeld RM, Amin R, Burns JJ, Darrow DH, Giordano T, Litman RS, Li KK, Mannix ME, Schwartz RH, Setzen G, Wald ER, Wall E, Sandberg G, Patel MM: Clinical practice guideline: Tonsillectomy in children. Otolaryngol Head Neck Surg 144: S1-S30, 2011.

Bharath V, Eckert K, Kang M, Chin-Yee IH, Hsia CC: Incidence and natural history of intravenous immunoglobulin-induced aseptic meningitis: A retrospective review at a single tertiary care center. Transfusion 55:2597-2605, 2015.

Brimberg L, Benhar I, Mascaro-Blanco A, Alvarez K, Lotan D, Winter C, Klein J, Moses AE, Somnier FE, Leckman JF, Swedo 
SE, Cunningham MW, Joel D: Behavioral, pharmacological, and immunological abnormalities after streptococcal exposure: A novel rat model of Sydenham chorea and related neuropsychiatric disorders. Neuropsychopharmacology 37:2076-2087, 2012.

Brown K, Farmer C, Farhadian B, Hernandez J, Thienemann M, Frankovich J: Pediatric acute-onset neuropsychiatric syndrome- response to oral corticosteroid bursts: An observational study in an academic community-based PANS clinic. J Child Adolesc Psychopharmacol 2017a. [Epub ahead of print]; DOI: 10.1089/cap.2016.0139

Brown K, Farmer C, Freeman GM, Spartz E, Farhadian B, Thienemann M, Frankovich J: Effect of early and prophylactic nonsteroidal anti-inflammatory drugs on flare duration in pediatric acute-onset neuropsychiatric syndrome: An observational study of patients followed by an academic community-based PANS clinic. J Child Adolesc Psychopharmacol 2017b. [Epub ahead of print]; DOI: 10.1089/cap.2016.0193

Candelario-Jalil E, Taheri S, Yang Y, Sood R, Grossetete M, Estrada EY, Fiebich BL, Rosenberg GA: Cyclooxygenase inhibition limits blood-brain barrier disruption following intracerebral injection of tumor necrosis factor-alpha in the rat. J Pharmacol Exp Ther 323:488-498, 2007.

Casey B, Vauss YC, Chused A, Swedo SE: Cognitive functioning in Sydenham's chorea: Part 2. Executive functioning. Dev Neuropsychol 10:89-96, 1994a.

Casey B, Vauss YC, Swedo SE: Cognitive functioning in Sydenham's chorea: Part 1. Attentional processes. Dev Neuropsychol 10:75-88, 1994b.

Chang K, Frankovich J, Cooperstock M, Cunningham MW, Latimer ME, Murphy TK, Pasternack M, Thienemann M, Williams K, Walter J, Swedo SE: Clinical evaluation of youth with pediatric acute-onset neuropsychiatric syndrome (PANS): Recommendations from the 2013 PANS Consensus Conference. J Child Adolesc Psychopharmacol 25:3-13, 2015.

Cherin P, Marie I, Michallet M, Pelus E, Dantal J, Crave JC, Delain JC, Viallard JF: Management of adverse events in the treatment of patients with immunoglobulin therapy: A review of evidence. Autoimmun Rev 15:71-81, 2016.

Cooperstock M, Swedo S, Pasternack M, Murphy T: Clinical management of pediatric acute-onset neuropsychiatric syndrome (PANS): Part III Treatment and prevention of infections. J Child Adolesc Psychopharmacol 2017. [Epub ahead of print]; DOI: 10.1089/cap.2016.0151

Costa-Reis P, Nativ S, Isgro J, Rodrigues T, Yildirim-Toruner C, Starr A, Saiman L, Imundo L, Eichenfield A: Major infections in a cohort of 120 patients with juvenile-onset systemic lupus erythematosus. Clin Immunol 149:442-449, 2013.

Cox CJ, Sharma M, Leckman JF, Zuccolo J, Zuccolo A, Kovoor A, Swedo SE, Cunningham MW: Brain human monoclonal autoantibody from Sydenham chorea targets dopaminergic neurons in transgenic mice and signals dopamine D2 receptor: Implications in human disease. J Immunol 191:5524-5541, 2013.

Cox CJ, Zuccolo AJ, Edwards EV, Mascaro-Blanco A, Alvarez K, Stoner J, Chang K, Cunningham MW: Antineuronal antibodies in a heterogeneous group of youth and young adults with tics and obsessive-compulsive disorder. J Child Adolesc Psychopharmacol 25:76-85, 2015

Cutforth T, DeMille MM, Agalliu I, Agalliu D: CNS autoimmune disease after infections: Animal models, cellular mechanisms and genetic factors. Future Neurol 11:63-76, 2016.

Da Silva JA, Jacobs JW, Kirwan JR, Boers M, Saag KG, Ines LB, de Koning EJ, Buttgereit F, Cutolo M, Capell H, Rau R, Bijlsma JW: Safety of low dose glucocorticoid treatment in rheumatoid arthritis: Published evidence and prospective trial data. Ann Rheum Dis 65:285-293, 2006.
Dale RC, Gorman MP, Lim M: Autoimmune encephalitis in children: Clinical phenomenology, therapeutics, and emerging challenges. Curr Opin Neurol 30:1-11, 2017.

Dalmau J, Lancaster E, Martinez-Hernandez E, Rosenfeld MR, Balice-Gordon R: Clinical experience and laboratory investigations in patients with anti-NMDAR encephalitis. Lancet Neurol 10:6374, 2011.

Dalsgaard S, Waltoft BL, Leckman JF, Mortensen PB: Maternal history of autoimmune disease and later development of Tourette syndrome in offspring. J Am Acad Child Adolesc Psychiatry 54:495-501, 2015.

Demesh D, Virbalas JM, Bent JP: The role of tonsillectomy in the treatment of pediatric autoimmune neuropsychiatric disorders associated with streptococcal infections (PANDAS). JAMA Otolaryngol Head Neck Surg 141:272-275, 2015.

Dileepan T, Smith ED, Knowland D, Hsu M, Platt M, Bittner-Eddy P, Cohen B, Southern P, Latimer E, Harley E, Agalliu D, Cleary PP: Group A Streptococcus intranasal infection promotes CNS infiltration by streptococcal-specific Th17 cells. J Clin Invest 126:303-317, 2016.

Duzova A, Bakkaloglu A: Central nervous system involvement in pediatric rheumatic diseases: Current concepts in treatment. Curr Pharm Des 14:1295-1301, 2008.

Elia J, Dell ML, Friedman DF, Zimmerman RA, Balamuth N, Ahmed AA, Pati S: PANDAS with catatonia: A case report. Therapeutic response to lorazepam and plasmapheresis. J Am Acad Child Adolesc Psychiatry 44:1145-1150, 2005.

Fazekas F, Deisenhammer F, Strasser-Fuchs S, Nahler G, Mamoli B: Randomised placebo-controlled trial of monthly intravenous immunoglobulin therapy in relapsing-remitting multiple sclerosis. Austrian Immunoglobulin in Multiple Sclerosis Study Group. Lancet 349:589-593, 1997.

Frankovich J, Thienemann M, Pearlstein J, Crable A, Brown K, Chang $\mathrm{K}$ : Multidisciplinary clinic dedicated to treating youth with pediatric acute-onset neuropsychiatric syndrome: Presenting characteristics of the first 47 consecutive patients. J Child Adolesc Psychopharmacol 25:38-47, 2015a.

Frankovich J, Thienemann M, Rana S, Chang K: Five youth with pediatric acute-onset neuropsychiatric syndrome of differing etiologies. J Child Adolesc Psychopharmacol 25:31-37, 2015b.

Fusco FR, Pompa A, Bernardi G, Ottaviani F, Giampa C, Laurenti D, Morello M, Bernardini S, Nuccetelli M, Sabatini U, Paolucci S: A case of PANDAS treated with tetrabenazine and tonsillectomy. J Child Neurol 25:614-615, 2010.

Garvey MA, Snider LA, Leitman SF, Werden R, Swedo SE: Treatment of Sydenham's chorea with intravenous immunoglobulin, plasma exchange, or prednisone. J Child Neurol 20:424-429, 2005.

Gaughan T, Buckley A, Hommer R, Grant P, Williams K, Leckman JF, Swedo SE: Rapid eye movement sleep abnormalities in children with pediatric acute-onset neuropsychiatric syndrome (PANS). J Clin Sleep Med 12:1027-1032, 2016.

Gerardi DM, Casadonte J, Patel P, Murphy TK: PANDAS and comorbid Kleine-Levin syndrome. J Child Adolesc Psychopharmacol 25:93-98, 2015.

Giedd JN, Rapoport JL, Garvey MA, Perlmutter S, Swedo SE: MRI assessment of children with obsessive-compulsive disorder or tics associated with streptococcal infection. Am J Psychiatry 157:281283, 2000 .

Giedd JN, Rapoport JL, Leonard HL, Richter D, Swedo SE: Case study: Acute basal ganglia enlargement and obsessive-compulsive symptoms in an adolescent boy. J Am Acad Child Adolesc Psychiatry 35:913-915, 1996.

Goodman WK, Price LH, Rasmussen SA, Mazure C, Delgado P, Heninger GR, Charney DS: The Yale-Brown Obsessive Compulsive Scale. II. Validity. Arch Gen Psychiatry 46:1012-1016, 1989. 
Graus F, Titulaer MJ, Balu R, Benseler S, Bien CG, Cellucci T, Cortese I, Dale RC, Gelfand JM, Geschwind M, Glaser CA, Honnorat J, Hoftberger R, lizuka T, Irani SR, Lancaster E, Leypoldt F, Pruss H, Rae-Grant A, Reindl M, Rosenfeld MR, Rostasy K, Saiz A, Venkatesan A, Vincent A, Wandinger KP, Waters P, Dalmau J: A clinical approach to diagnosis of autoimmune encephalitis. Lancet Neurol 15:391-404, 2016.

Guy W: ECDEU Assessment Manual for Psychopharmacology. Rockville (Maryland), U.S. Dept. of Health, Education, and Welfare, Public Health Service, Alcohol, Drug Abuse, and Mental Health Administration, National Institute of Mental Health, Psychopharmacology Research Branch, Division of Extramural Research Programs, 1976.

Hachiya Y, Miyata R, Tanuma N, Hongou K, Tanaka K, Shimoda K, Kanda S, Hoshino A, Hanafusa Y, Kumada S, Kurihara E, Hayashi M: Autoimmune neurological disorders associated with group-A beta-hemolytic streptococcal infection. Brain Dev 35:670-674, 2013.

Hahn BH, McMahon MA, Wilkinson A, Wallace WD, Daikh DI, Fitzgerald JD, Karpouzas GA, Merrill JT, Wallace DJ, Yazdany J, Ramsey-Goldman R, Singh K, Khalighi M, Choi SI, Gogia M, Kafaja S, Kamgar M, Lau C, Martin WJ, Parikh S, Peng J, Rastogi A, Chen W, Grossman JM: American College of Rheumatology guidelines for screening, treatment, and management of lupus nephritis. Arthritis Care Res (Hoboken) 64:797-808, 2012.

Hahn BH, Singh RR, Wong WK, Tsao BP, Bulpitt K, Ebling FM: Treatment with a consensus peptide based on amino acid sequences in autoantibodies prevents $\mathrm{T}$ cell activation by autoantigens and delays disease onset in murine lupus. Arthritis Rheum 44:432-441, 2001.

Hashkes PJ, Laxer RM: Medical treatment of juvenile idiopathic arthritis. JAMA 294:1671-1684, 2005.

Heubi C, Shott SR: PANDAS: Pediatric autoimmune neuropsychiatric disorders associated with streptococcal infections-An uncommon, but important indication for tonsillectomy. Int J Pediatr Otorhinolaryngol 67:837-840, 2003.

Hirschtritt ME, Hammond CJ, Luckenbaugh D, Buhle J, Thurm AE, Casey BJ, Swedo SE: Executive and attention functioning among children in the PANDAS subgroup. Child Neuropsychol 15:179194, 2009.

Hoekstra PJ, Minderaa RB, Kallenberg CG: Lack of effect of intravenous immunoglobulins on tics: A double-blind placebocontrolled study. J Clin Psychiatry 65:537-542, 2004.

Hoffman KL, Hornig M, Yaddanapudi K, Jabado O, Lipkin WI: A murine model for neuropsychiatric disorders associated with group A beta-hemolytic streptococcal infection. J Neurosci 24:17801791, 2004.

Hornig M: The role of microbes and autoimmunity in the pathogenesis of neuropsychiatric illness. Curr Opin Rheumatol 25:488-795, 2013.

Hornig M, Lipkin WI: Immune-mediated animal models of Tourette syndrome. Neurosci Biobehav Rev 37:1120-1138, 2013.

Hughes RA, Swan AV, van Doorn PA: Intravenous immunoglobulin for Guillain-Barre syndrome. Cochrane Database Syst Rev CD002063, 2014.

Husby G, van de Rijn I, Zabriskie JB, Abdin ZH, Williams RC, Jr: Antibodies reacting with cytoplasm of subthalamic and caudate nuclei neurons in chorea and acute rheumatic fever. J Exp Med 144:1094-1110, 1976.

Iniguez MA, Punzon C, Fresno M: Induction of cyclooxygenase- 2 on activated $\mathrm{T}$ lymphocytes: Regulation of $\mathrm{T}$ cell activation by cyclooxygenase-2 inhibitors. J Immunol 163:111-119, 1999.

Jones JV, Robinson MF, Parciany RK, Layfer LF, McLeod B: Therapeutic plasmapheresis in systemic lupus erythematosus. Effect on immune complexes and antibodies to DNA. Arthritis Rheum 24:1113-1120, 1981.

Kirvan CA, Cox CJ, Swedo SE, Cunningham MW: Tubulin is a neuronal target of autoantibodies in Sydenham's chorea. J Immunol 178:7412-7421, 2007.

Kirvan CA, Swedo SE, Heuser JS, Cunningham MW: Mimicry and autoantibody-mediated neuronal cell signaling in Sydenham chorea. Nat Med 9:914-920, 2003.

Kirvan CA, Swedo SE, Kurahara D, Cunningham MW: Streptococcal mimicry and antibody-mediated cell signaling in the pathogenesis of Sydenham's chorea. Autoimmunity 39:21-29, 2006 a.

Kirvan CA, Swedo SE, Snider LA, Cunningham MW: Antibodymediated neuronal cell signaling in behavior and movement disorders. J Neuroimmunol 179:173-179, 2006b.

Kovacevic M, Grant P, Swedo SE: Use of intravenous immunoglobulin in the treatment of twelve youths with pediatric autoimmune neuropsychiatric disorders associated with streptococcal infections. J Child Adolesc Psychopharmacol 25:65-69, 2015.

Kumar A, Williams MT, Chugani HT: Evaluation of basal ganglia and thalamic inflammation in children with pediatric autoimmune neuropsychiatric disorders associated with streptococcal infection and Tourette syndrome: A positron emission tomographic (PET) study using 11C-[R]-PK11195. J Child Neurol 30:749-756, 2015.

Latimer ME, L'Etoile N, Seidlitz J, Swedo SE: Therapeutic plasma apheresis as a treatment for 35 severely ill children and adolescents with pediatric autoimmune neuropsychiatric disorders associated with streptococcal infections. J Child Adolesc Psychopharmacol 25:70-75, 2015.

Leach JP, Chadwick DW, Miles JB, Hart IK: Improvement in adultonset Rasmussen's encephalitis with long-term immunomodulatory therapy. Neurology 52:738-742, 1999.

Lewin AB, Storch EA, Mutch PJ, Murphy TK: Neurocognitive functioning in youth with pediatric autoimmune neuropsychiatric disorders associated with streptococcus. J Neuropsychiatry Clin Neurosci 23:391-398, 2011.

Lotan D, Benhar I, Alvarez K, Mascaro-Blanco A, Brimberg L, Frenkel D, Cunningham MW, Joel D: Behavioral and neural effects of intra-striatal infusion of anti-streptococcal antibodies in rats. Brain Behav Immun 38:249-262, 2014.

Mackenzie IRA, Munoz DG: Nonsteroidal anti-inflammatory drug use and Alzheimer type pathology in aging. Neurology 50:986-990, 1998.

Magro-Checa C, Zirkzee EJ, Huizinga TW, Steup-Beekman GM: Management of neuropsychiatric systemic lupus erythematosus: Current approaches and future perspectives. Drugs 76:459-483, 2016.

Müller N, Ulmschneider M, Scheppach C, Schwarz MJ, Ackenheil M, Möller HJ, Gruber R, Riedel M: COX-2 inhibition as a treatment approach in schizophrenia: Immunological considerations and clinical effects of celecoxib add-on therapy. Eur Arch Psychiatry Clin Neurosci 254:14-22, 2004.

Murphy BS, Sundareshan V, Cory TJ, Hayes D, Anstead MI, Feola DJ: Azithromycin alters macrophage phenotype. J Antimicrob Chemother 61:554-560, 2008.

Murphy T, Brennan E, Johnco C, Parker-Athill E, Miladinovic B, Storch E, Lewin A: A double blind randomized placebo-controlled pilot study of azithromycin in youth with acute obsessive compulsive disorder. J Child Adolesc Psychopharmacol 2017. [Epub ahead of print]; DOI: 10.1089/cap.2016.0190

Murphy TK, Lewin AB, Parker-Athill EC, Storch EA, Mutch PJ: Tonsillectomies and adenoidectomies do not prevent the onset of pediatric autoimmune neuropsychiatric disorder associated with group A streptococcus. Pediatr Infect Dis J 32:834-838, 2013.

Murphy TK, Patel PD, McGuire JF, Kennel A, Mutch PJ, Parker-Athill EC, Hanks CE, Lewin AB, Storch EA, Toufexis MD, Dadlani GH, 
Rodriguez CA: Characterization of the pediatric acute-onset neuropsychiatric syndrome phenotype. J Child Adolesc Psychopharmacol 25:14-25, 2015.

Murphy TK, Storch EA, Turner A, Reid JM, Tan J, Lewin AB: Maternal history of autoimmune disease in children presenting with tics and/or obsessive-compulsive disorder. J Neuroimmunol 229:243247,2010

Napolitani G, Acosta-Rodriguez E V., Lanzavecchia A, Sallusto F: Prostaglandin E2 enhances Th17 responses via modulation of IL-17 and IFN- $\gamma$ production by memory CD4+ T cells. Eur J Immunol 39:1301-1312, 2009.

Neuwelt CM: The role of plasmapheresis in the treatment of severe central nervous system neuropsychiatric systemic lupus erythematosus. Ther Apher Dial 7:173-182, 2003.

Newburger JW, Takahashi M, Beiser AS, Burns JC, Bastian J, Chung KJ, Colan SD, Duffy CE, Fulton DR, Glode MP, Mason WH, Meissner HC, Rowley AH, Shulman ST, Reddy V, Sundel RP, Wiggins JW, Colton T, Melish ME, Rosen FS: A Single intravenous infusion of gamma globulin as compared with four infusions in the treatment of acute Kawasaki syndrome. N Engl J Med 324:1633-1639, 1991.

Nicolson R, Swedo SE, Lenane M, Bedwell J, Wudarsky M, Gochman P, Hamburger SD, Rapoport JL: An open trial of plasma exchange in childhood-onset obsessive-compulsive disorder without poststreptococcal exacerbations. J Am Acad Child Adolesc Psychiatry 39:1313-1315, 2000.

Nosadini M, Mohammad SS, Ramanathan S, Brilot F, Dale RC: Immune therapy in autoimmune encephalitis: A systematic review. Expert Rev Neurother 15:1391-1419, 2015.

Nosadini M, Mohammad SS, Suppiej A, Sartori S, Dale RC: Intravenous immunoglobulin in paediatric neurology: Safety, adherence to guidelines, and long-term outcome. Dev Med Child Neurol 58:1180-1192, 2016.

Obregon D, Parker-Athill EC, Tan J, Murphy T: Psychotropic effects of antimicrobials and immune modulation by psychotropics: Implications for neuroimmune disorders. Neuropsychiatry (London) 2:331-343, 2012.

Orange JS, Hossny EM, Weiler CR, Ballow M, Berger M, Bonilla FA, Buckley R, Chinen J, El-Gamal Y, Mazer BD, Nelson RP, Jr, Patel DD, Secord E, Sorensen RU, Wasserman RL, CunninghamRundles C: Use of intravenous immunoglobulin in human disease: A review of evidence by members of the Primary Immunodeficiency Committee of the American Academy of Allergy, Asthma and Immunology. J Allergy Clin Immunol 117:S525-S553, 2006.

Pavone P, Rapisarda V, Serra A, Nicita F, Spalice A, Parano E, Rizzo R, Maiolino L, Di Mauro P, Vitaliti G, Coco A, Falsaperla A, Trifiletti RR, Cocuzza S: Pediatric autoimmune neuropsychiatric disorder associated with group a streptococcal infection: The role of surgical treatment. Int J Immunopathol Pharmacol 27:371-378, 2014.

Paz JA, Silva CAA, Marques-Dias MJ: Randomized double-blind study with prednisone in Sydenham's chorea. Pediatr Neurol 34:264-269, 2006.

Perlmutter SJ, Leitman SF, Garvey MA, Hamburger S, Feldman E, Leonard HL, Swedo SE: Therapeutic plasma exchange and intravenous immunoglobulin for obsessive-compulsive disorder and tic disorders in childhood. Lancet 354:1153-1158, 1999.

Pierce LR, Jain N: Risks associated with the use of intravenous immunoglobulin. Transfus Med Rev 17:241-251, 2003.

Pohl D, Benseler S: Systemic inflammatory and autoimmune disorders. Handb Clin Neurol 112:1243-1252, 2013.

Rappold LC, Denk K, Enk AH, Hadaschik EN: Comparison of highdose intravenous immunoglobulin (IVIG) in a $5 \%$ and a $10 \%$ solution does not reveal a significantly different spectrum of side-effects. J Eur Acad Dermatol Venereol 30:e186-e188, 2015.

Rostasy K, Wilken B, Baumann M, Muller-Deile K, Bieber I, Gartner J, Moller P, Angelini P, Hero B: High dose pulsatile dexamethasone therapy in children with opsoclonus-myoclonus syndrome. Neuropediatrics 37:291-295, 2006.

Ruperto N, Nikishina I, Pachanov ED, Shachbazian Y, Prieur AM, Mouy R, Joos R, Zulian F, Schwarz R, Artamonova V, Emminger W, Bandeira M, Buoncompagni A, Foeldvari I, Falcini F, Baildam E, Kone-Paut I, Alessio M, Gerloni V, Lenhardt A, Martini A, Hanft G, Sigmund R, Simianer S: A randomized, double-blind clinical trial of two doses of meloxicam compared with naproxen in children with juvenile idiopathic arthritis: Short- and long-term efficacy and safety results. Arthritis Rheum 52:563-572, 2005.

Sayyah M, Boostani H, Pakseresht S, Malayeri A: A preliminary randomized double-blind clinical trial on the efficacy of celecoxib as an adjunct in the treatment of obsessive-compulsive disorder. Psychiatry Res 189:403-406, 2011.

Shaffer D, Gould MS, Brasic J, Ambrosini P, Fisher P, Bird H, Aluwahlia S: A children's global assessment scale (CGAS). Arch Gen Psychiatry 40:1228-1231, 1983.

Shalbafan M, Mohammadinejad P, Shariat SV, Alavi K, Zeinoddini A, Salehi M, Askari N, Akhondzadeh S: Celecoxib as an adjuvant to fluvoxamine in moderate to severe obsessive-compulsive disorder: A double-blind, placebo-controlled, randomized trial. Pharmacopsychiatry 48:136-140, 2015.

Sharma S, Jaffe A, Dixon G: Immunomodulatory effects of macrolide antibiotics in respiratory disease: Therapeutic implications for asthma and cystic fibrosis. Paediatr Drugs 9:107-118, 2007.

Singer HS, Mascaro-Blanco A, Alvarez K, Morris-Berry C, Kawikova I, Ben-Pazi H, Thompson CB, Ali SF, Kaplan EL, Cunningham MW: Neuronal antibody biomarkers for Sydenham's chorea identify a new group of children with chronic recurrent episodic acute exacerbations of tic and obsessive compulsive symptoms following a streptococcal infection. PLoS One 10:e0120499, 2015.

Slattery MJ, Dubbert BK, Allen AJ, Leonard HL, Swedo SE, Gourley MF: Prevalence of obsessive-compulsive disorder in patients with systemic lupus erythematosus. J Clin Psychiatry 65:301-306, 2004.

Sobel RE, Lovell DJ, Brunner HI, Weiss JE, Morris PW, Gottlieb BS, Chalom EC, Jung LK, Onel KB, Petiniot L, Goldsmith DP, Nanda K, Shishov M, Abramsky S, Young JP, Giannini EH: Safety of celecoxib and nonselective nonsteroidal anti-inflammatory drugs in juvenile idiopathic arthritis: Results of the phase 4 registry. Pediatr Rheumatol Online J 12:29, 2014.

Spartz E, Freeman GM, Brown KD, Farhadian B, Thienemann M, Frankovich J: Course of neuropsychiatric symptoms after introduction or removal of non-steroidal anti-inflammatory drugs: A pediatric observational study. J Child Adolesc Psychopharmacol 2017. [Epub ahead of print]; DOI: 10.1089/cap.2016.0179

Swedo SE, Leckman JF, Rose NR: Modifying the PANDAS criteria to describe PANS (pediatric acute-onset neuropsychiatric syndrome). Pediatr Ther 2:1-8, 2012.

Swedo SE, Leonard HL, Garvey M, Mittleman B, Allen AJ, Perlmutter S, Lougee L, Dow S, Zamkoff J, Dubbert BK: Pediatric autoimmune neuropsychiatric disorders associated with streptococcal infections: Clinical description of the first 50 cases. Am J Psychiatry 155:264-271, 1998.

Szczepiorkowski ZM, Bandarenko N, Kim HC, Linenberger ML, Marques MB, Sarode R, Schwartz J, Shaz BH, Weinstein R, Wirk A, Winters JL: Guidelines on the use of therapeutic apheresis in clinical practice: Evidence-based approach from the Apheresis Applications Committee of the American Society for Apheresis. J Clin Apheresis 22:106-175, 2007. 
Thienemann M, Murphy T, Williams K, Leckman J, Shaw R, Geller D, Kapphahn C, Frankovich J, Elia J, Chang K, Hommer R, Swedo $\mathrm{S}$ : Clinical management of pediatric acute-onset neuropsychiatric syndrome (PANS): Part I-Psychiatric and behavioral interventions. J Child Adolesc Psychopharmacol 2017. [Epub ahead of print]; DOI: 10.1089/cap.2016.0145

Thornby KA, Henneman A, Brown DA: Evidence-based strategies to reduce intravenous immunoglobulin-induced headaches. Ann Pharmacother 49:715-726, 2015.

Titulaer MJ, McCracken L, Gabilondo I, Armangue T, Glaser C, Iizuka T, Honig LS, Benseler SM, Kawachi I, Martinez-Hernandez E, Aguilar E, Gresa-Arribas N, Ryan-Florance N, Torrents A, Saiz A, Rosenfeld MR, Balice-Gordon R, Graus F, Dalmau J: Treatment and prognostic factors for long-term outcome in patients with antiNMDA receptor encephalitis: An observational cohort study. Lancet Neurol 12:157-165, 2013.

Toufexis MD, Hommer R, Gerardi DM, Grant P, Rothschild L, 'D'Souza P, Williams K, Leckman J, Swedo SE, Murphy TK: Disordered eating and food restrictions in children with PANDAS/ PANS. J Child Adolesc Psychopharmacol 25:48-56, 2015.

Tucker DM, Leckman JF, Scahill L, Wilf GE, LaCamera R, Cardona L, Cohen P, Heidmann S, Goldstein J, Judge J, Snyder E, Bult A, Peterson BS, King R, Lombroso P: A putative poststreptococcal case of OCD with chronic tic disorder, not otherwise specified. J Am Acad Child Adolesc Psychiatry 35:1684-1691, 1996.

Van Mater H: Pediatric inflammatory brain diseases: A diagnostic approach. Curr Opin Rheumatol 26:553-561, 2014.

Vernino S, Geschwind M, Boeve B: Autoimmune encephalopathies. Neurologist 13:140-147, 2007.

Walker AR, Tani LY, Thompson JA, Firth SD, Veasy LG, Bale JF: Rheumatic chorea: Relationship to systemic manifestations and response to corticosteroids. J Pediatr 151:679-683, 2007.

Wallace CA, Giannini EH, Spalding SJ, Hashkes PJ, O'Neil KM, Zeft AS, Szer IS, Ringold S, Brunner HI, Schanberg LE, Sundel RP, Milojevic DS, Punaro MG, Chira P, Gottlieb BS, Higgins GC, Ilowite NT, Kimura Y, Johnson A, Huang B, Lovell DJ: Clinically inactive disease in a cohort of children with new-onset polyarticular juvenile idiopathic arthritis treated with early aggressive therapy:
Time to achievement, total duration, and predictors. J Rheumatol 41:1163-1170, 2014.

Weinstein R: Therapeutic apheresis in neurological disorders: A survey of the evidence in support of current category I and II indications for therapeutic plasma exchange. J Clin Apheresis 23:196-201, 2008.

Williams KA, Swedo SE: Post-infectious autoimmune disorders: Sydenham's chorea, PANDAS and beyond. Brain Res 1617:144154, 2015.

Williams KA, Swedo SE, Farmer CA, Grantz H, Grant PJ, D'Souza P, Hommer R, Katsovich L, King RA, Leckman JF: Randomized, controlled trial of intravenous immunoglobulin for pediatric autoimmune neuropsychiatric disorders associated with streptococcal infections. J Am Acad Child Adolesc Psychiatry 55:860-867, 2016.

Wong PH, White KM: Impact of immunoglobulin therapy in pediatric disease: A review of immune mechanisms. Clin Rev Allergy Immunol 51:303-314, 2016.

Yaddanapudi K, Hornig M, Serge R, De Miranda J, Baghban A, Villar G, Lipkin WI: Passive transfer of streptococcus-induced antibodies reproduces behavioral disturbances in a mouse model of pediatric autoimmune neuropsychiatric disorders associated with streptococcal infection. Mol Psychiatry 15:712-726, 2010.

Zandman-Goddard G, Krauthammer A, Levy Y, Langevitz P, Shoenfeld Y: Long-term therapy with intravenous immunoglobulin is beneficial in patients with autoimmune diseases. Clin Rev Allergy Immunol 42:247-255, 2012.

Address correspondence to: Jennifer Frankovich, MD, MS Division of Pediatrics Department of Pediatric Rheumatology Stanford University School of Medicine 700 Welch Road Suite 301, MC: 5896 Palo Alto, CA 94304

E-mail: jfranko@stanford.edu 


\section{Appendix}

Table A1. Use of Nonsteroidal Anti-Inflammatory Drugs in Pediatric ACUte-OnSET Neuropsychiatric Syndrome

Indication: Use in patients with mild impairment.

Administration: Take with food, milk, or antacid to decrease GI adverse effects.

Precautions: Use sunscreen concurrently with NSAIDs. Maintain a well hydrated state. Discontinue if patient restricts fluids or has risk of dehydration for other reasons (intense sports in hot weather). Do not take concurrently with ethanol or other liver toxic medications. Use with caution if patient is on corticosteroids. Do not use while patient is on high-dose corticosteroids. Consider temporary discontinuation if patient develops viral gastroenteritis. Do not use if patient has moderate-to-severe swallow dysfunction because of risk of esophageal erosion if NSAID is not properly swallowed.

Adverse effects: CNS (drowsiness, dizziness, and blurred vision); GI (nausea, gastritis, esophageal erosion, gastrointestinal reflux disease, constipation, diarrhea, decreased appetite, and rectal bleeding; elevated liver enzymes); skin (photophobic reactions including pseudoporphyria skin rash and sun sensitivity); psychiatric symptoms (anxiety, depression, fatigue, and nervousness); hematology (epistaxis, hematuria, hematoma, and rectal hemorrhage); and cardiovascular (hypertension).

Monitoring: Periodic trials off of NSAIDs every 6 weeks. If a patient repeatedly deteriorates when NSAID is discontinued, it can be restarted and continued in the long term with continued trials off (every 1.5-6 months) or do a trial of corticosteroids to abort PANS flare. Laboratory work every 3-6 months if patient is on NSAIDs continuously: liver enzymes, BUN, creatinine, CBC with differential, and UA.

Mechanism: Inhibits prostaglandin synthesis by decreasing the activity of cyclooxygenase, which results in decreased formation of prostaglandin precursors. NSAIDs have antipyretic, analgesic, and anti-inflammatory properties. NSAIDs may also have immunomodulatory effects by decreasing the following immune responses: $T$ cell proliferation and the production of proinflammatory cytokines (Iniguez et al. 1999), the Th17 response (Napolitani et al. 2009), and microglial activation (Mackenzie and Munoz 1998). It may also decrease blood-brain barrier permeability (Candelario-Jalil et al. 2007).

\begin{tabular}{|c|c|c|c|}
\hline & Dosage & Preparation & Consideration \\
\hline (1) Ibuprofen & $\begin{array}{l}10 \mathrm{mg} / \mathrm{kg} \text { every } 6-8 \text { hours } \\
\text { (maximum } 600 \mathrm{mg} / \mathrm{dose} \text { ) }\end{array}$ & $\begin{array}{l}\text { Tablet, chewable, } \\
\text { capsules, or } \\
\text { liquid. }\end{array}$ & $\begin{array}{l}\text { Requires frequent dosing to maintain continuous } \\
\text { anti-inflammatory action. Available OTC. Liquid } \\
\text { and chewable preparations taste better than } \\
\text { naproxen. }\end{array}$ \\
\hline (2) Naproxen & $\begin{array}{l}10 \mathrm{mg} / \mathrm{kg} \text { every } 12 \mathrm{hours} \\
\quad(\mathrm{maximum} 500 \mathrm{mg} / \mathrm{dose})\end{array}$ & $\begin{array}{l}\text { Tablets, capsules, } \\
\text { or liquid. }\end{array}$ & $\begin{array}{l}\text { Naproxen is a potent long-acting NSAID that only } \\
\text { requires twice daily dosing. Generally tolerated by } \\
\text { children. Liquid formulation available as } \\
\text { prescription }(250 \mathrm{mg} / 5 \mathrm{~mL}) \text { but the taste is often } \\
\text { intolerable. }\end{array}$ \\
\hline (3) Sulindac & $\begin{array}{l}2-4 \mathrm{mg} / \mathrm{kg} \cdot \text { day every } 12 \text { hours; } \\
\text { maximum } 6 \mathrm{mg} / \mathrm{kg} \cdot \text { day; do } \\
\text { not exceed } 400 \mathrm{mg} / \text { day }\end{array}$ & $\begin{array}{l}\text { Tablets; can be } \\
\text { compounded into } \\
\text { a suspension. }\end{array}$ & $\begin{array}{l}\text { Sulindac is equal in potency to naproxen and is also } \\
\text { long acting. It may have fewer GI side effects. }\end{array}$ \\
\hline (4) Celecoxib & $\begin{array}{l}\text { 10-25 kg: } 50 \mathrm{mg} \text { twice a day } \\
>25 \mathrm{~kg}: 100 \mathrm{mg} \text { twice a day }\end{array}$ & $\begin{array}{l}\text { Capsules; can be } \\
\text { compounded into } \\
\text { a suspension. }\end{array}$ & $\begin{array}{l}\text { Fewer GI side effects. Less potent than naproxen and } \\
\text { sulindac but helpful if patient develops gastritis } \\
\text { symptoms on other NSAIDs. }\end{array}$ \\
\hline
\end{tabular}

BUN, blood urea nitrogen; CBC, complete blood count; CNS, central nervous system; GI, gastrointestinal; NSAIDs, nonsteroidal anti-inflammatory drugs; OTC, over-the-counter; PANS, pediatric acute-onset neuropsychiatric syndrome; UA, urine analysis.

Table A2. Use of Corticosteroids in Pediatric Acute-Onset Neuropsychiatric Syndrome

Indications: Used to abort PANS flare. If used early in disease course, it can abort or shorten flare duration and theoretically minimize vascular and tissue inflammation/damage (Brown et al. 2017a). Introduction of corticosteroids late in the flare is less likely to result in dramatic responses and will require higher doses or more prolonged courses. If patient has longstanding untreated disease, a chronicstatic, or a chronic-progressive course, a longer course of corticosteroids (oral burst+taper or weekly/monthly pulsing \pm adjunct immunotherapy) will be needed. More sophisticated brain imaging techniques are needed to help clinicians definitively determine presence of neuroinflammation; but in the absence of this technology, corticosteroid trials can guide the clinician in determining whether inflammation is playing a role in a brain disorder. If the child's symptoms improve in the weeks after an adequate corticosteroid trial (dosing based on disease trajectory and severity, Table 3), this suggests that inflammation may be driving the psychiatric symptoms.

Administration: Take with food, milk, or antacid to decrease GI adverse effects. Ensure adequate vitamin D levels and adequate consumption of calcium. Consider calcium and vitamin D supplementation.

Precautions: Corticosteroids should be used with caution and only in the setting wherein caregivers can manage likely escalation in psychiatric symptoms. Rapid withdrawal of steroids can cause pseudotumor cerebri and other headache syndromes. Corticosteroidinduced hypertension can cause headaches. Combination of NSAIDs and corticosteroids may lead to gastritis. 
TABle A2. (Continued)

Psychiatric/behavior side effects: Temporary increase in obsessive-compulsive symptoms, tics, irritability, rage, psychosis, emotional lability, depressed or fluctuating mood, behavior regression, insomnia, life-threatening impulsivity, and behavioral outbursts can occur while the corticosteroids are in the body. Symptoms resolve rapidly in the days after a short course (i.e., 5-day oral prednisone burst) but take longer to resolve when a prolonged course is given (i.e., prednisone burst+taper) or when high-dose corticosteroids are used (i.e., oral dexamethasone pulse or IV methylprednisolone pulses described hereunder).

Physical side effects that occur with prolonged courses, frequent oral prednisone bursts, or high-dose corticosteroids: Temporary effects may include blurry vision, weight gain, Cushingoid appearance, altered glucose metabolism, dyslipidemia, and hypertension. Temporary effects resolve in the weeks to months after cessation of corticosteroids. Time to resolution of these temporary side effects is proportional to duration of time on corticosteroids and intensity of dosing (i.e., the more saturated the body, the longer it will take to normalize). Permanent effects may include cataracts, glaucoma, bone infarcts, osteopenia, type-2 diabetes, hypertension, and striae. IV methylprednisolone infusions can cause hypertension or hypotension, tachycardia or bradycardia, blurry vision, flushing, sweating, and metallic taste in mouth. Weekly or monthly corticosteroid pulses (see hereunder) are thought to have fewer physical side effects as compared with prolonged oral prednisone courses.

Monitoring: If prolonged courses, frequent bursts, or high-dose corticosteroids are used, the following should be considered: periodic ophthalmological examinations to evaluate for cataracts and glaucoma, imaging of painful limbs to evaluate for avascular necrosis of bones and/or referral to orthopedics, assessment/precautions for osteopenia, $\mathrm{HbA1C}$, routine blood pressure monitoring, and periodic assessment of dyslipidemia.

Mechanisms: Potent anti-inflammatory and immunosuppressive effects through multiple mechanisms, including down regulation of cytokine gene expression in leukocytes and down regulation of leukocyte adhesion molecule gene expression in endothelial cells (thus inhibiting adhesion-dependent leukocyte migration from the vascular space into extravascular tissues).

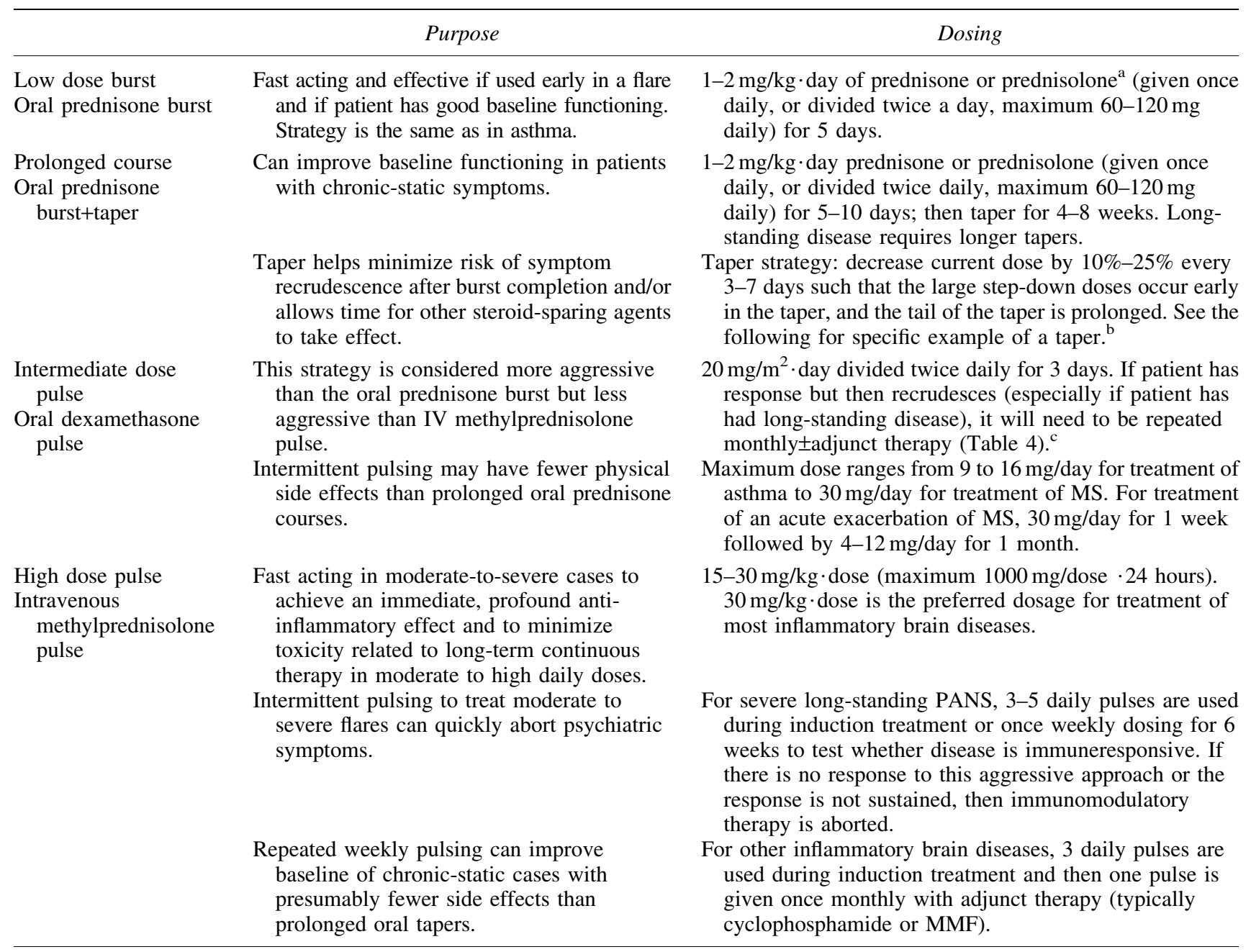

${ }^{a}$ If liquid formulation is desired, use prednisolone because it tastes better and is more readily available as compared with prednisone.

${ }^{\mathrm{b}}$ For example: $30 \mathrm{mg}$ BID for 5-10 days; then step dose down every 3-7 days according to the following: $30 \mathrm{mg}$ in AM/20 mg in PM; $30 \mathrm{mg}$ in AM/10 mg in $\mathrm{PM} ; 30 \mathrm{mg}$ in AM only; $25 \mathrm{mg}$ in AM only; $20 \mathrm{mg}$ in AM; $17.5 \mathrm{mg}$ in AM; $15 \mathrm{mg}$ in AM; $12.5 \mathrm{mg}$ in AM; $10 \mathrm{mg}$ in AM; $7.5 \mathrm{mg}$ in AM; then $5 \mathrm{mg}$ in AM. Many patients start having recrudescence after tapering $<15 \mathrm{mg}$, so further taper may have to be suspended until after another agent (e.g., IVIG) is initiated.

${ }^{c}$ This approach was derived from a protocol used to treat opsiclonus-myoclonus syndrome, which is a presumed CNS autoimmune disease in children (Rostasy et al. 2006).

CNS, central nervous system; GI, gastrointestinal; HbA1C, hemoglobin A1C; IV, intravenous; IVIG, intravenous immunoglobulin; MMF, mycophenolate mofetil; MS, multiple sclerosis; NSAIDs, nonsteroidal anti-inflammatory drugs; PANS, pediatric acute-onset neuropsychiatric syndrome. 
Table A3. Use of Corticosteroid-Sparing Agents in Pediatric Acute-Onset Neuropsychiatric Syndrome

\begin{tabular}{|c|c|c|c|}
\hline & Description/benefit & Adverse effects & Dosing \\
\hline \multirow[t]{2}{*}{ IVIG } & $\begin{array}{l}\text { IVIG is derived from pooled } \\
\text { plasma from human donors } \\
\text { and processed using rigorous } \\
\text { purification steps. }\end{array}$ & $\begin{array}{l}\text { Common infusion-related side effects } \\
\text { include nausea, myalgia, fever, chills, } \\
\text { rigors, chest discomfort, and } \\
\text { hypotension (often dose related or } \\
\text { because of rapid administration). }\end{array}$ & $\begin{array}{l}\text { Induction: } 1.5-2 \mathrm{~g} / \mathrm{kg} \text {, maximum dose } \\
70 \mathrm{~g} / \mathrm{dose} \text {. If patient has clear } \\
\text { improvement and then recrudesces, } \\
\text { subsequent doses should be dosed at } 1 \mathrm{~g} / \\
\mathrm{kg} \text {. Second and third doses have been } \\
\text { given at } 4-6 \text {-week intervals by PANS } \\
\text { Consortium members. }\end{array}$ \\
\hline & $\begin{array}{l}\text { Several potential } \\
\text { immunomodulatory roles } \\
\text { including effects on } \mathrm{Fc}\end{array}$ & $\begin{array}{l}\text { Postinfusion headaches (HA) }{ }^{\mathrm{a}} \text { are common } \\
\text { including aseptic-like meningitis. } \\
\text { Aggressive hydration pre/post and half }\end{array}$ & $\begin{array}{l}\text { Some patients are treated with } \\
\text { rheumatology protocols that utilize } 2 \mathrm{~g} / \\
\text { kg monthly (maximum dose } 70 \mathrm{~g} / \mathrm{dose} \text { ). }\end{array}$ \\
\hline
\end{tabular}

receptor activity (saturating

$\mathrm{FcR}$ ) and $\mathrm{F}(\mathrm{ab}) 2$ activity (antiidiotypic antibodies) and other mechanisms.

Benefit: Broadly impacts immune function and autoimmune responses and may help moderate the autoantibody responses.

Caution: The authors report rare cases of worsening PANS symptoms after IVIG when IVIG is given around the time of a new viral illness.

TPE

Removes autoantibodies triggering immune responses leading to brain inflammation

TPE is a process of separating blood components using centrifugation and a semipermeable membrane. This allows for diseasepromoting blood components to be removed while the remaining components are returned to the patient. Plasma proteins, including antibodiespromoting disease, can be removed from the patient's blood.

Benefit: Rapidly removes antibodies from plasma and quickly eliminates autoreactive immune responses caused by antibodies. way through IVIG infusion can help minimize HA. Use of OTC NSAIDs or corticosteroids during and after IVIG can also help prevent/manage HA.

A transient fever can be seen in the first 24 hours. Rarely, symptomatic hemolysis can occur and manifest up to 1-week postinfusion. Anaphylaxis can occur, especially in patients with IgA deficiency (if IgA deficient, use formulation that does not contain $\operatorname{IgA}$ ). Other rare side effects include renal failure, thrombosis (including sinus venous thrombosis), dermatological reactions, hemolytic reactions, neutropenia, transfusion-related lung injury, and seizures.

TPE often requires an intensive care admission and this may be psychiatrically traumatizing to some children.

Related to IV access: pain, bleeding, infection, and, thrombosis. Risks of sedation. Risks of fluid shifts. Complications related to citrate anticoagulation/calcium chelating, and replaced with albumin. Risks of exposure to blood products.

Syncope, pseudoseizures, and pain amplification have been reported immediately after TPE.

TPE can cause hypogammaglobulinemia.
If patient becomes dependent on IVIG to maintain good baseline, consider adding in or replacing with rituximab or MMF.

1 volume therapeutic exchanges every other day for 10-12 days (5-6 runs) (Perlmutter et al. 1999).

1.5 volume therapeutic exchanges for 3-5 days (3-4 runs) (Latimer et al. 2015).

As soon as TPE is stopped, autoantibodies will continue to be produced (if autoimmune disease is present), thus adjunct therapy is recommended. In infection-triggered PANS, TPE alone can be effective if infectious driver is eliminated. 
TABle A3. (Continued)

\begin{tabular}{|c|c|c|c|}
\hline & Description/benefit & Adverse effects & Dosing \\
\hline Rituximab & $\begin{array}{l}\text { FDA approved for use in } \\
\text { microscopic polyangiitis, } \\
\text { granulomatosis with } \\
\text { polyangiitis (formerly } \\
\text { Wegener's), and rheumatoid } \\
\text { arthritis. It is frequently used } \\
\text { in idiopathic } \\
\text { thrombocytopenic purpura, } \\
\text { lupus nephritis, and } \\
\text { autoimmune encephalitis. } \\
\text { A chimeric antibody directed } \\
\text { against CD20, a surface } \\
\text { protein found on B cells that } \\
\text { leads to rapid B cell depletion. } \\
\text { Benefit: B cell depletion } \\
\text { frequently occurs within } \\
24-48 \text { hours after infusion and } \\
\text { can be sustained for } 3 \text { months } \\
\text { to }>1 \text { year. In chronic-static or } \\
\text { refractory cases, benefits may } \\
\text { not be seen for } 6 \text { months. }\end{array}$ & $\begin{array}{l}\text { PANS patients can have escalation of } \\
\text { psychiatric symptoms and pain } \\
\text { symptoms after the first round (lasting } \\
1-5 \text { months), but the second round at } 6 \\
\text { months is generally better tolerated. } \\
\text { Infusion reactions are frequent, especially } \\
\text { with the first dose, but can be mitigated } \\
\text { by slowing the infusion rate and } \\
\text { premedication with corticosteroids, } \\
\text { acetaminophen, and diphenhydramine. } \\
\text { Serious infections have been reported } \\
\text { but are rare. Reported infections after } \\
\text { rituximab include CMV-related retinitis/ } \\
\text { colitis, progressive myelitis } \\
\text { leukoencephalipathy (JC virus), } \\
\text { pneumonia, and empyema. }\end{array}$ & $\begin{array}{l}\text { Most autoimmune diseases are treated with } \\
\text { the protocol used in rheumatoid arthriti } \\
\text { of } 750 \mathrm{mg} / \mathrm{m}^{2} \text { (maximum dose } \\
1000 \mathrm{mg}) \times 2 \text { doses separated by } 2 \\
\text { weeks. Although the effect can last up to } \\
\text { a year, many patients relapse at the } \\
\text { 6-month mark so most protocols aimed } \\
\text { to treat chronic autoimmune disease } \\
\text { require redosing at } 6 \text {-month intervals. }\end{array}$ \\
\hline MMF & $\begin{array}{l}\text { An inhibitor of inosine } \\
\text { monophosphate } \\
\text { dehydrogenase, a rate-limiting } \\
\text { enzyme for de novo synthesis } \\
\text { of guanosine nucleotides. } \\
\text { Several potential } \\
\text { immunomodulatory roles } \\
\text { including inhibition of } \\
\text { lymphocyte proliferation, } \\
\text { suppression of glycosylation } \\
\text { and expression of some } \\
\text { adhesion molecules, and } \\
\text { suppression of nitric oxide. } \\
\text { Benefit: Decreased B and T } \\
\text { lymphocyte proliferation. } \\
\text { Decreased antibody response. } \\
\text { Induction of apoptosis of } \\
\text { activated T lymphocytes. } \\
\text { Decreased lymphocyte and } \\
\text { monocyte recruitment to sites } \\
\text { of inflammation. Suppression } \\
\text { of tissue damage. }\end{array}$ & $\begin{array}{l}\text { Pans patients can have sensory } \\
\text { disturbances after introduction, } \\
\text { generally better tolerated when patient } \\
\text { is remitting on induction corticosteroids. } \\
\text { Common side effects include cytopenia, } \\
\text { dizziness, nausea, diarrhea, and } \\
\text { abdominal pain. Rare side effects } \\
\text { include dermatologic reactions, } \\
\text { hemolytic reactions, and abnormal renal } \\
\text { or hepatic function tests. } \\
\text { Increased risk of infections and sepsis. } \\
\text { Reported infections following MMF } \\
\text { include: CMV, herpes zoster, BK virus, } \\
\text { hepatitis B, and hepatitis C. Malignant } \\
\text { neoplasms have been reported but } \\
\text { are rare. }\end{array}$ & $\begin{array}{l}\text { MMF: } 600 \mathrm{mg} / \mathrm{m}^{2} / \text { dose twice daily ( } \max \\
\text { dose } 1500 \mathrm{mg} / \text { dose) } \\
\text { For patients who do not tolerate MMF, } \\
\text { mycophenolic acid (MPA) can be used } \\
\text { but has a different dosing regimen. }\end{array}$ \\
\hline
\end{tabular}

${ }^{a}$ IVIG-related headaches generally respond well to steroids $(1-2 \mathrm{mg} / \mathrm{kg}$ prednisone equivalent, maximum dose $60-120 \mathrm{mg} / \mathrm{day})$ when given along with and/or 2-5 days after the infusions. For patients who do not tolerate corticosteroids, NSAIDs can be used (IV ketorolac or ibuprofen around the clock). Premedication with diphenhydramine (or other antihistamines) and acetaminophen can also improve tolerability. Nausea can be treated with ondansetron and it may be needed around the clock during and after the infusion. Some patients may need opiates to manage severe headaches.

CMV, cytomegalovirus; IgA, immunoglobulin A; IV, intravenous; IVIG, intravenous immunoglobulin; JC, John Cunningham; MMF, mycophenolate mofetil; OTC, over the counter; PANS, pediatric acute-onset neuropsychiatric syndrome; TPE, therapeutic plasma exchange. 